Article

\title{
An Integrated Method to Evaluate Sustainability for Vulnerable Buildings Addressing Life Cycle Embodied Impacts and Resource Use
}

\author{
Fatma Seyma Keskin*(D), Pedro Martinez-Vazquez and Charalampos Baniotopoulos \\ Department of Civil Engineering, School of Engineering, University of Birmingham, Edgbaston, \\ Birmingham B15 2TT, UK; p.vazquez@bham.ac.uk (P.M.-V.); c.baniotopoulos@bham.ac.uk (C.B.) \\ * Correspondence: fseyma@outlook.com
}

Citation: Keskin, F.S.;

Martinez-Vazquez, P.; Baniotopoulos, C. An Integrated Method to Evaluate Sustainability for Vulnerable Buildings Addressing Life Cycle Embodied Impacts and Resource Use. Sustainability 2021, 13, 10204. https://doi.org/10.3390/su131810204

Academic Editors: Konstantinos Daniel Tsavdaridis,

Agathoklis Giaralis and

Keerthan Poologanathan

Received: 20 July 2021

Accepted: 9 September 2021

Published: 13 September 2021

Publisher's Note: MDPI stays neutral with regard to jurisdictional claims in published maps and institutional affiliations.

Copyright: (c) 2021 by the authors. Licensee MDPI, Basel, Switzerland. This article is an open access article distributed under the terms and conditions of the Creative Commons Attribution (CC BY) license (https:/ / creativecommons.org/licenses/by/ $4.0 /)$.

\begin{abstract}
The vulnerability of buildings faces further scrutiny as gaps in design, construction, operation, and maintenance remain. Although there has been noticeable progress in the field, the frequency and magnitude of building damage during natural events highlight the fact that sustainable infrastructure has not yet reached all targets. In this study, sustainability aspects of vulnerable buildings are revisited to propose more robust measures to prevent damage and a lack of functionality. Those measured are underpinned by the merging of environmental and structural sustainability for one novel integrated approach. The method devises structural intervention scenarios based on damage levels and service period. It also aims at reducing resource use and embodied impacts through the discretization of standard life cycle analysis into customized stages. The integrated method to evaluate sustainability is tested on two vulnerable buildings in Turkey and Mexico, built with different codes of practice and having experienced low to medium damage during severe earthquake events. Research findings indicate that although embodied impacts form a minor part of the building life cycle environmental impacts, sustainable structural interventions can further reduce both embodied impacts and demands on natural resources. Hence strengthening vulnerable buildings can provide an advantage to help the sustainable transformation of cities.
\end{abstract}

Keywords: vulnerable buildings; structural strengthening; environmental sustainability; life cycle; environmental assessment; embodied carbon; embodied energy; resource use; Turkey; Mexico

\section{Introduction}

\subsection{Background}

Vulnerability is defined for buildings as the degree of loss resulting from a hazard at a certain severity level [1] and depends on the reduction in resistance and the level of decay in the structures as a result of constant exposure to environmental factors (such as seismic actions) [2]. That impact has more than quadrupled between 1970 and 2018 [3], with the most destructive disasters in the last 20 years starting with events that took place between 2005 and 2006, which destroyed or heavily damaged the houses of more than 6 million people [4]. Earthquakes are considered as the deadliest phenomena [5], as their occurrence collapses vulnerable buildings, therefore causing high numbers of casualties [6]. To increase the resistance of buildings, they would naturally need to meet upgraded safety requirements. However, the necessary progress for pre-disaster preparedness, including the renewal of building codes, is far behind in developing countries compared to developed countries [6]. Added to that, post-disaster preparedness is also rare in these countries [7]. A third factor to consider is the fact that population growing trends concentrate in megacities, while projections spanning the next 50 years suggest that one earthquake event in one such a city may cause up to 1 million deaths [8], hence our suggesting that current vulnerable building stock will increase exponentially. 
The environmental sustainability of the buildings adds problems once the building sector is highly responsible for world energy consumption and carbon dioxide $\left(\mathrm{CO}_{2}\right)$ emissions. While the total energy use during the operation and construction of the building sector has reached $36 \%$ of global final energy use, $\mathrm{CO}_{2}$ emissions from buildings have generated about $40 \%$ of the world's total emissions [9]. For instance, greenhouse gas (GHG) emissions are one of the sources of air pollution, and buildings are individually responsible for more than half of emissions by the built environment. This air pollution caused by energy use in buildings globally kills half a million each year [10]. To an extent, this latent problem reflects the inability of construction industries in keeping up or engaging with other sectors in developing and enforcing sustainability methods and procedures. In such a context, energy-efficient measures and the efficient use of resources (building materials) offer opportunities for reducing emissions [11], while life cycle assessment (LCA) frameworks provide tools and instruments to quantify environmental impacts, taking into account lifetime flows between nature and building from cradle-to-grave [12].

\subsection{State of the Art of the Life Cycle Environmental Impact Assessment of Vulnerable Buildings}

Buildings consume energy and emit pollutants throughout their entire life. This occurs through embodied and operational energy and carbon. Embodied impacts span the manufacturing and end-of-life stages of a building, whereas operational impacts refer to its use [13]. Figure 1 illustrates this distinction through stages and system boundaries, including representative modules according to EN 15,978 [14] and Annex 57 [15]. Embodied impacts load the environment through resource depletion and the pollution of water, air and soil, and embodied energy can constitute $10-20 \%$ of the energy demand of a building from cradle-to-grave (regarding both residential and office buildings) [16]. Carbon emissions occur during manufacturing, on-site construction, repair, deconstruction, and mainly the construction stage because of the large energy consumption [17]; the manufacturing of building materials takes up about $20 \%$ of the world's fuel consumption [18]. Furthermore, the manufacturing phase depletes natural resources and generates significant amounts of debris from demolition. Evidence of this is the approximately 89 billion tons (Gt) of natural resources consumed in 2017 globally. The construction sector consumed $44 \mathrm{Gt}$ from the global account of non-metallic materials, and this amount is set to increase to $86 \mathrm{Gt}$ by 2060 [19]. This adds to the fact that the operation of buildings causes the highest energy consumption and accompanying GHG emissions amongst other human-led activities [20]. Therefore, most sustainability initiatives and techniques aim at cutting down the operational energy to nearly zero while excluding embodied energy.

Modern techniques for reducing energy and carbon emissions related to buildings focus on energy upgrading. This has revealed that existing building stock could not provide sufficient energy saving; most crucially, this expansive stock continues deteriorating, which increases vulnerability to seismic motions [21]. For this reason, Feroldi et al. [22], Mora et al. [23], Marini et al. [21], Georgescu et al. [24], Basirico and Enea [25], De Vita et al. [26], Mora et al. [27], and Lamperti et al. [28] have worked to increase structural safety through energy retrofitting mostly focused on building envelopes that provide thermal comfort. However, these studies do not foresee merging the assessment of structural and environmental performance [29] while excluding the embodied carbon and energy caused by structural deficiencies in reported life cycle analyses.

As sustainability best practice manages to reduce operational energy, the research focus will slightly shift to tackle material-related embodied impacts [30]. To date, traditional LCA frameworks have been partially insufficient to assess a building's environmental performance accurately, particularly when environmental loss due to destructive disasters needs addressing [31]. It is worth noting that the quantification of building environmental impacts includes the entire process from construction to maintenance and replacements [32]. However, no equivalent database exists for the environmental impacts of post-disaster repair or the reconstruction of buildings in the historical loss data in the form of cost data associated with damage repair [5]. As a result, various studies have estimated the 
environmental impacts derived from the repair probabilistically. These are mostly focused on seismic damage, and therefore integrate performance-based earthquake engineering (PBEE) methods [33]. These use HAZUS and/or PACT tools to calculate earthquakeinduced losses probabilistically, considering uncertainties associated with seismic events, relate damage probabilities $[34,35]$ and relevant repair costs that can be adopted to calculate environmental impacts [36]. This adoption has been conducted through three different pathways [33], namely, repair cost ratio (ratio between repair cost and replacement cost of a building) [37-40], EIO-LCA (economic input-output life cycle assessment) [41,42], and LCA according to repair description $[5,31,32,36,43-50]$. In recent years, the integration methods and standards have increased substantially; however, no consensus has been created on the best-integrated approach [33]. Part of the complexity of finding the optimal approximation is the need to fulfil hazard-resistant design [46], which tends to be a highly technical subject compared with standard LCA. The hazard-resistant design should also cover pre- and post-disaster construction and repair for existing vulnerable buildings.

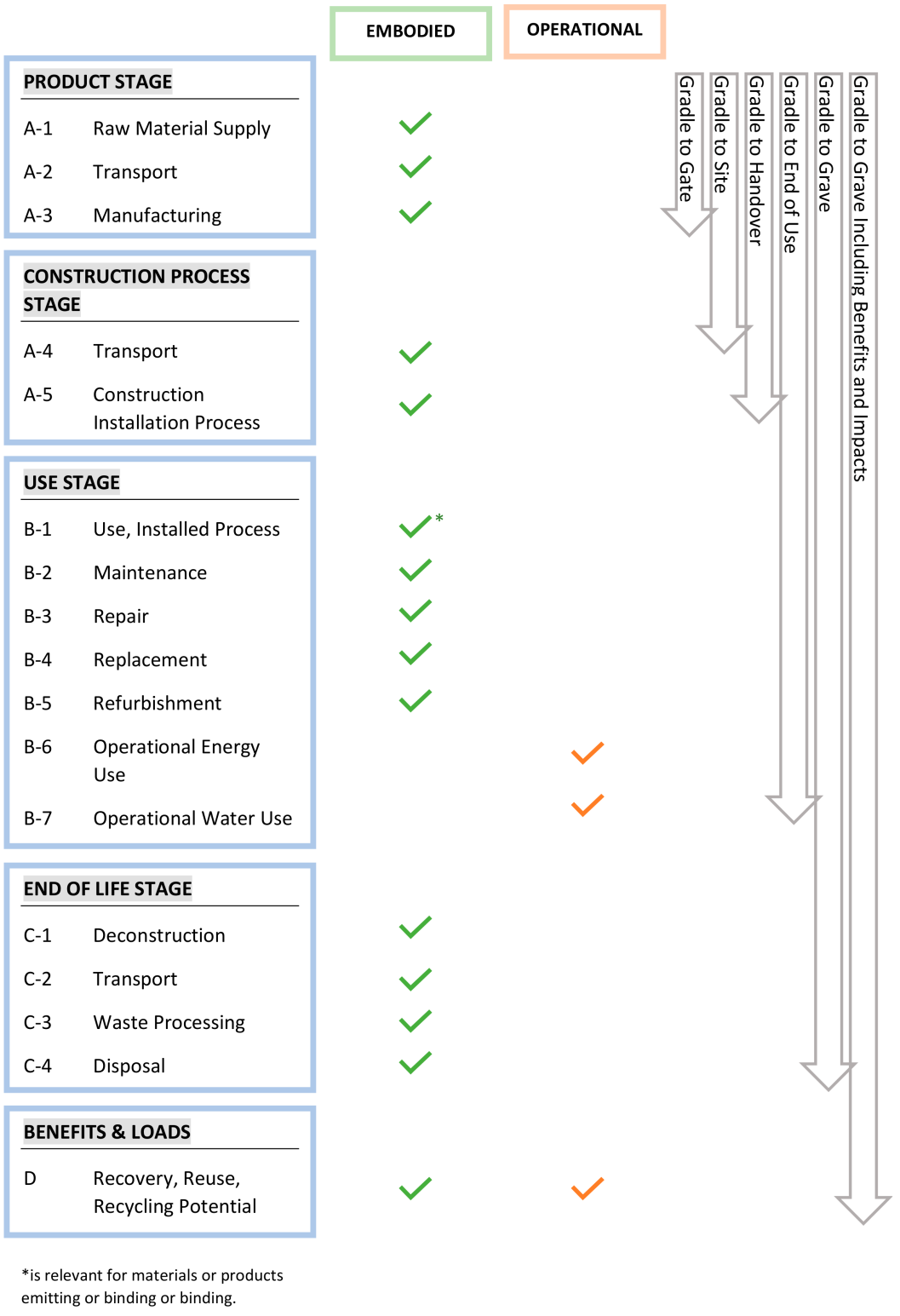

Figure 1. Embodied and operational impacts over building life cycle stages $[14,60]$.

Due to retrofitting of post-disaster buildings being characterized by an extended lifespan, including versatile and adaptable design procedures and solutions, data collection, and interpretations [51], existing probabilistic assessments may not be sufficient for the 
sustainable transformation of existing vulnerable buildings. At this point, real-world applications of retrofitting can be investigated to assess their environmental impacts [38]. Some studies [47,51-58] focused on structural retrofitting of the existing building and their environmental impacts. Some $[29,59]$ combine structural and sustainability metrics with economic terms implemented by monetizing $\mathrm{CO}_{2}$ emissions. These studies are inherently specific to a particular region and seismic events, which makes them difficult to use elsewhere, as building performance objectives may vary, or conversely, performance-based standards may target different objectives [34]. The process of recovering existing buildings requires integrated multidisciplinary approaches; hence it is crucial to identify ongoing interactions [26]. Existing buildings provide a great advantage to avoid new environmental impacts. Since they have already released embodied carbon during their construction, keeping them in service for as long as possible helps to amortize this carbon debt by avoiding new emissions from demolition or new building construction [12]. Added to this, the multiple deficiencies that characterize vulnerable infrastructure demand better insight into the new resilience target in response to a disaster. In this study, these deficiencies are scrutinized from an environmental sustainability perspective to understand the life cycle impacts of vulnerable buildings, considering extended and designed service periods. Therefore, an integrated method is developed that gives a simplified and improved framework based on alternative scenarios considering different damage scales and local codes for structures, including Pre-LCA and LCA stages.

This study proposes embedding structural interventions for vulnerable buildings into LCA and evaluates its effectiveness by estimating life cycle-embodied impacts and resource use through the scrutiny of various scenarios involving customized LCA stages. Moreover, this investigation identifies the potential advantages of the existing building stock by increasing its functionality, which, to date, is mostly considered a structural and environmental burden.

The paper is organized into five sections. Section 2 presents the proposed methodology and discusses how it could be implemented. Sections 3 and 4 present case studies of low and medium-damaged buildings, respectively. Section 5 provides a concise discussion and some final remarks.

\section{Proposed Sustainability Framework}

The Sustainable Structural Intervention Method (SSIM) prioritizes different ways to measure the environmental benefits of structural retrofit. It does integrate structural intervention impacts into the standard LCA framework through the concatenation of PreLCA and LCA stages. Pre-LCA covers the design of intervention scenarios, which leads to the pursuit of sustainable construction. The LCA stage further scrutinizes the building life cycle stages for vulnerable buildings from cradle-to-grave according to their service life. These two stages are interdependent, and therefore require mechanisms to exchange information. Previous research undertaken by this author presents the simple outline of the proposed method [61]. The method is further scrutinized and comprehensively developed in this study and applied to two case studies.

The case studies use old buildings originally designed and constructed under different paradigms; the aim then was to provide enough durability against severe earthquakes as defined by local building regulations. In theory, compliance with these regulations minimizes the direct and indirect impacts of the hazard [49]; therefore, it may not completely prevent damage. In line with this philosophy, certain levels of damage may occur in buildings, and one of the solutions is structural strengthening. Demolition is perhaps the most common end for damaged buildings because of the difficulties related to affordability for structural retrofitting, or its applicability. In addition, urban transformation projects can facilitate the demolition of vulnerable buildings. Therefore, the replacement of the vulnerable building is considered in this study as an intervention scenario to assess the environmental impacts of retrofitted and new buildings. The SSIM now includes the evaluation of potential scenarios by using two alternative paths: to determine (1) which retrofit design 
minimizes environmental impacts (type of intervention to use) and (2) which decisions for retrofitted or non-retrofitted designs achieve the lowest environmental impacts (end-of-life procedure). To be able to reflect these different paths, the case studies defined as low- and medium-damaged refer to "type of intervention to use" and "end-of-life procedure", respectively. These two paths are unfolded in Figure 2 to better illustrate how the assessment process spans Pre-LCA and LCA stages-bearing in mind the extended service life and new design life provided by the latter.

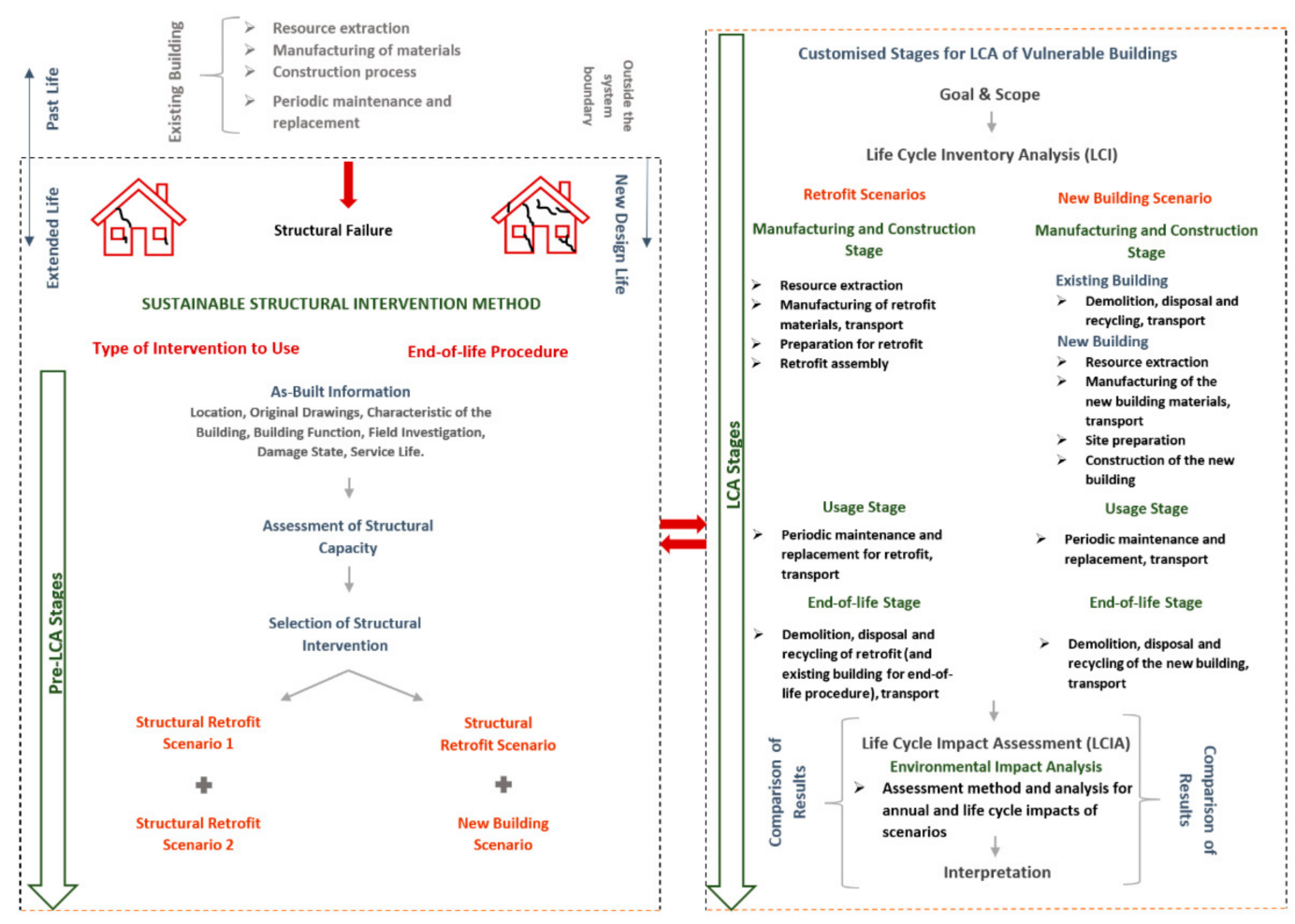

Figure 2. Simplified framework of the proposed method SSIM.

LCA stages are constrained by system boundaries labeled cradle-to-grave in ISO 14040. However, it has been suggested that system boundaries are shaped alongside the overall goal of the study [62]. For example, EN 15,978 [14] presents specific LCA stages integrating the selection of building components and subsequent construction; however, these stages would need further scrutiny to address specific conditions of damage and the actions to take during the structural recovery of vulnerable buildings. As structural improvements can cause a massive intervention in the vulnerable buildings, the full transformation of these interventions on vulnerable buildings into their life cycle sustainability should be included, such as retrofit assembly, debris from retrofit assembly and its disposal, and maintenance of the retrofit. In addition to that, in case of the replacement of the vulnerable building, the demolition and disposal process of the vulnerable building should be considered. Life cycle impacts related to disaster damages should therefore add to the standard life cycle impacts of a building, and altogether be assessed through customized stages [63]. In this way, particular requirements derived from interventions can become part of an integrated approach [64]. LCA stages addressing structural interventions should therefore allow the proper reflection of vulnerability in buildings. This is also reflected in Figure 2, where the LCA stages of structural intervention branch out into a specific parameterization spanning between raw material extraction and the end of life.

The following sections discuss the stages and paths of the SSIM for two damaged buildings. The first case study is a low-damaged building suitable for two different retrofitting techniques, and replacement of the building has not been the object. In this respect, the first case study is shown as an example for the alternative path, type of 
intervention use. In the second case study, a massive structural retrofit was applied, and the replacement of the building has been considered in the project planning stage. In this case, this medium-damaged building was deemed suitable for the alternative path, end-of-life procedure.

\section{Type of Intervention to Use}

This alternative path was followed for the sustainable design of a low-damaged building for which at least two different strengthening techniques can be identified. The below sections highlight the steps to follow during the Pre-LCA and LCA stages of the interventions.

\subsection{Pre-LCA of the Low-Damaged Building}

\subsubsection{As-Built Information}

The case study uses a residential reinforced concrete (RC) building located in Van, Turkey. This region stands as one of the most seismically active in the world. Past events include the 2011 Van earthquake, which reached a magnitude of 7.2 Mw and severely damaged $30 \%$ of the buildings in the area [65].

The property comprises a semi-detached building based on rigid frames-see Figure 3. It has seven floors with a mix of usages. The basement served as a storage area, the ground and mezzanine floors as commercial, while the four upper floors were for residential use. After the retrofitting, the usage slightly changed; the top apartment floors were used as a hotel, whereas the rest of the floors remained operating as before. Architectural and structural details of the project were outsourced by the project engineer.
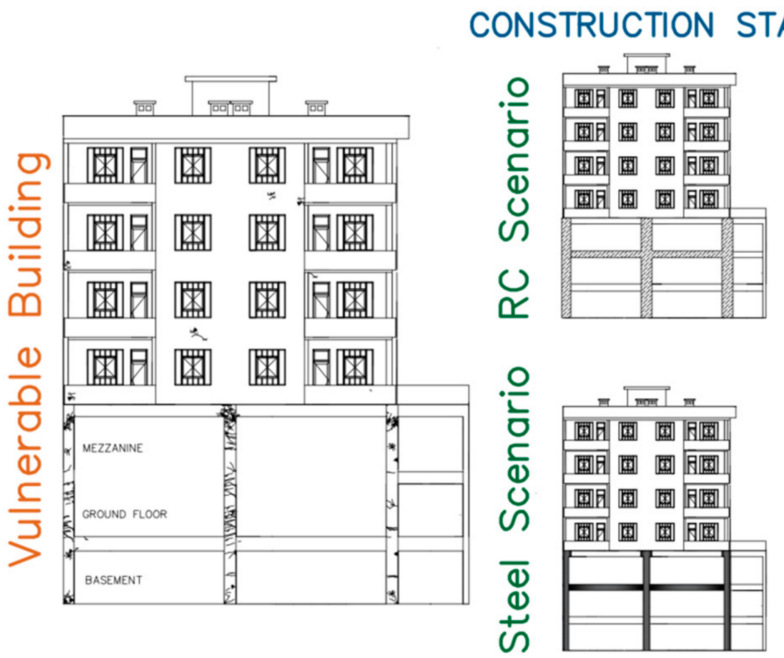
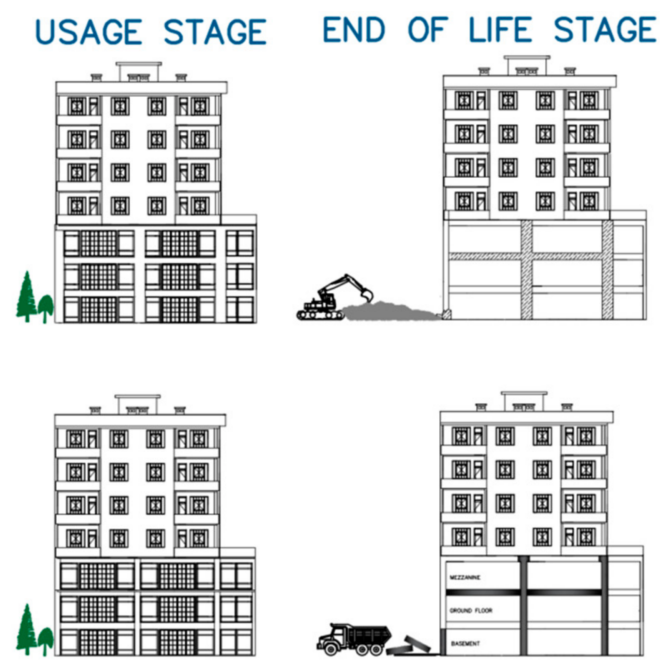

Figure 3. Schematic representation of a low-damaged building's LCA stages over two selected scenarios.

The facility went through a visual inspection to gather initial information, such as geometry, type, location, and level of the damage, including that to the existing load-bearing system. Destructive and non-destructive tests were performed to infer the mechanical properties of materials. Horizontal cracks were observed at the lower and upper ends of the columns of the basement, ground, and mezzanine floors. There were other cracks on upper floor slabs, whereas some beams had vertical deflections. The building had some local floor openings to enable an easy view of the retail store from outside and inside the building. Added to this, structural beams were not placed in this area for aesthetic reasons. These failures caused low stiffness at the ground and mezzanine floors. Therefore, the damage would have been caused by the previously mentioned geometrical irregularities.

The building was constructed in 2001; hence its damage during the earthquake would not have been expected, bearing in mind that a residential or commercial building is usually designed with a life span of 50 years [66]. Design service life recommendations for 
buildings are given depending on the procedure applied. For instance, British standards recommend $<10,>10,>30,>60$ and $>120$ years, and Canadian standards recommend $<10$, $10-24,25-49,50-99$ and $>100$ years, depending on the building function; however, the Japanese guides go beyond them and suggest 3, 6, 10, 15, 25, 40, 60, 100 and 150 years [67]. Estimation of service life has subjective values based on various factors, such as quality of materials, the service life of building components, building facility and environmental conditions, as interpreted by the designer [68]. According to the project engineer, the retrofit facility could continue serving for another 65 years.

\subsubsection{Assessment of Structural Capacity}

The building was constructed following the 1998 earthquake codes, and the quality of the materials was found to be suitable. The former study determined that floor openings and other geometrical irregularities prevented a proper transference of seismic forces amongst structural elements. A post-failure analysis of the structure was completed in 2012 by the project engineer following the 2007 Earthquake Regulations in Turkey. This included static and dynamic nonlinear analyses, which enabled the conclusion that this building does not meet the conditions stipulated by the regulation and will not perform safely in the event of another earthquake. The structure, therefore, required retrofitting to upgrade its performance level.

\subsubsection{Selection of Structural Interventions}

To strengthen columns, designers decided to use standard concrete/steel and CFRP (carbon fiber-reinforced polymers) jacketing methods. They also implemented additional beams around existing openings to facilitate the load transfer across rigid frames. Upper floors' beams and ceilings were also strengthened where some cracking was identified. The reinforced structure was then modeled to find the most economical and statically correct system beyond the refinement of the initially proposed retrofit. Derived from this process, the two retrofit scenarios shown in Table 1 were identified.

Table 1. Selected structural strengthening scenarios for the damaged building.

\begin{tabular}{|c|c|}
\hline RC Scenario & Steel Scenario \\
\hline RC jacketing ( 9 columns) & Steel jacketing (11 columns) \\
\hline & Steel beam additions for the ground floor \\
\hline $\mathrm{RC}$ beam additions ( 3 of them $40 \times 40 \mathrm{~cm}$ and & (hollow structural steel with $10 \mathrm{~mm}$ thickness) \\
\hline 1 of them $70 \times 32 \mathrm{~cm}$ ) for the ground floor & $\begin{array}{l}\text { and U-shaped plates to the column-beam joints } \\
\text { in the mezzanine floor }\end{array}$ \\
\hline $\begin{array}{l}\text { CFPR application to deflected beams and } \\
\text { cracked ceiling concrete }\end{array}$ & $\begin{array}{l}\text { CFPR application to deflected beams and } \\
\text { cracked ceiling concrete }\end{array}$ \\
\hline Epoxy application to cracks & Epoxy application to cracks \\
\hline
\end{tabular}

\subsection{LCA of the Low-Damaged Building}

LCA stages followed to assess the environmental impacts of the two structural intervention scenarios. The same applications in both scenarios were eliminated (CFRP application to the deflected beams and cracked ceiling surfaces are the same in both scenarios), as it would not make a difference for the comparison of the LCA results of the strengthening scenarios.

\subsubsection{Goal and Scope}

This case study aims at a sustainability performance comparison of two types of structural retrofit. The analysis will run from the materials' production to the end-of-life stage and beyond building life (BBL) in the LCA boundary system, spanning from A to D, as shown in Figure 1. 


\subsubsection{Life Cycle Inventory (LCI)}

LCI includes the quantification of retrofit materials, construction works, transportation, maintenance, and end-of-life, and feeds into the retrofit's customized LCA stages. The flow chart shown in Figure 3 illustrates the steps to follow in the analysis. The bill of materials (BOM) was generated based on the actual drawings and data collected Pre-LCA, including information gathered through research as well as a few reasonable assumptions. The latter was supported by the Athena Impact Estimator for Buildings (AIEB) tool, addressing onsite construction, related transportation, replacement and maintenance works, demolition, disposal and recycling (as per the BOM and building's service life). For the usage stage, only painting works were included for the hotel's 65 years' service life, with a maintenance frequency set to five years. Only retrofit materials, their deconstruction and final disposal were considered for the end-of-life stage; the rest of the building components were excluded. Figure 4 shows the adopted RC and steel-strengthening interventions.

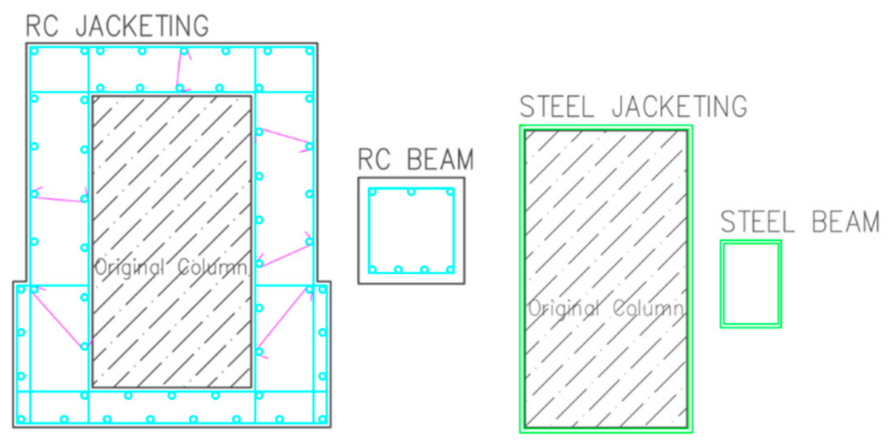

Figure 4. One of the examples of RC and steel reinforcements.

\subsubsection{Life Cycle Impact Assessment (LCIA)}

The author tested several LCA software programs to finally select AIEB for assessing environmental burdens induced by material and energy consumption. This is apparently the only available tool for assessing the whole set of building environmental impacts [69]. This case study incorporates system boundaries established in AIEB into customized LCA stages. For instance, retrofit assemblies generate construction waste (such as concrete drilling) that should be removed during the process; hence the construction process includes disposal in addition to material waste. The LCI profile created with AIEB then went through filtering so that characterization factors based on TRACI (Tool for Reduction and Assessment of Chemicals and Other Environmental Impacts) methodologies could be added [69].

\section{Resource Use Analysis Results}

The use of resources for each scenario includes whole stages (A to D). The extraction of materials for manufacturing and construction involves high material and energy consumption levels, while the end-of-life includes the quantification of energy for material transport. Table 2 provides the total quantification of resources for both scenarios, showing that the RC scenario consumes more resources than its steel equivalent.

Table 2. The resource use of both scenarios.

\begin{tabular}{llll}
\hline \multirow{2}{*}{ Material } & Unit & \multicolumn{2}{l}{ Resource Use } \\
\cline { 3 - 4 } & & RC Scenario & Steel Scenario \\
\hline Ash & $\mathrm{kg}$ & $5.57 \mathrm{E}+01$ & $2.25 \mathrm{E}+01$ \\
Bauxite & $\mathrm{kg}$ & $2.64 \mathrm{E}+01$ & $2.44 \mathrm{E}+00$ \\
Carbon dioxide, in air & $\mathrm{kg}$ & $4.16 \mathrm{E}+02$ & $1.72 \mathrm{E}+02$ \\
Clay and shale & $\mathrm{kg}$ & $1.18 \mathrm{E}+02$ & $1.09 \mathrm{E}+01$ \\
Coal & $\mathrm{kg}$ & $3.04 \mathrm{E}+03$ & $2.85 \mathrm{E}+03$ \\
Coarse aggregate & $\mathrm{kg}$ & $5.40 \mathrm{E}+04$ & $2.81 \mathrm{E}+03$ \\
\hline
\end{tabular}


Table 2. Cont.

\begin{tabular}{llll}
\hline \multirow{2}{*}{ Material } & Unit & \multicolumn{2}{l}{ Resource Use } \\
\cline { 3 - 4 } & & RC Scenario & Steel Scenario \\
\hline Crude oil & $\mathrm{L}$ & $1.38 \mathrm{E}+03$ & $5.93 \mathrm{E}+02$ \\
Crude oil as feedstock & $\mathrm{L}$ & $1.85 \mathrm{E}+02$ & $1.31 \mathrm{E}+02$ \\
Dolomite & $\mathrm{kg}$ & $3.95 \mathrm{E}+02$ & $7.95 \mathrm{E}+02$ \\
Ferrous scrap & $\mathrm{kg}$ & $6.09 \mathrm{E}+03$ & $1.05 \mathrm{E}+04$ \\
Gypsum (natural) & $\mathrm{kg}$ & $3.91 \mathrm{E}+02$ & $3.78 \mathrm{E}+01$ \\
Gypsum (synthetic) & $\mathrm{kg}$ & $4.79 \mathrm{E}+01$ & $1.90 \mathrm{E}+01$ \\
Iron ore & $\mathrm{kg}$ & $2.70 \mathrm{E}+03$ & $2.17 \mathrm{E}+03$ \\
Lignite & $\mathrm{kg}$ & $6.73 \mathrm{E}+01$ & $2.67 \mathrm{E}+02$ \\
Limestone & $\mathrm{kg}$ & $1.14 \mathrm{E}+04$ & $2.00 \mathrm{E}+03$ \\
Natural gas & $\mathrm{m}$ & $7.71 \mathrm{E}+02$ & $2.06 \mathrm{E}+03$ \\
Natural gas as feedstock & $\mathrm{m}$ & $2.48 \mathrm{E}+02$ & $1.55 \mathrm{E}+02$ \\
Other & $\mathrm{kg}$ & $9.56 \mathrm{E}+02$ & $2.89 \mathrm{E}+02$ \\
Peat & $\mathrm{kg}$ & $6.55 \mathrm{E}-02$ & $2.26 \mathrm{E}-02$ \\
Sand & $\mathrm{kg}$ & $7.77 \mathrm{E}-04$ & $2.84 \mathrm{E}-04$ \\
Tin ore & $\mathrm{kg}$ & $2.66 \mathrm{E}-06$ & $3.96 \mathrm{E}-07$ \\
Uranium & $\mathrm{kg}$ & $2.35 \mathrm{E}-02$ & $3.89 \mathrm{E}-02$ \\
Water & $\mathrm{L}$ & $1.88 \mathrm{E}+05$ & $1.50 \mathrm{E}+05$ \\
Wood fiber & $\mathrm{kg}$ & $9.89 \mathrm{E}+02$ & $1.55 \mathrm{E}+01$ \\
\hline
\end{tabular}

Embodied Carbon and Energy Analysis Results

The environmental impacts attributed to each retrofit scenario are presented over their complete life cycle. The LCI starts with the extraction of raw materials, followed by waste, energy and land use during extraction before raw materials are transported to the plant. The construction stage includes on-site construction activities and energy use for transportation from the manufacturer to the distribution center, and from there to the building site. Waste generation is also evaluated at this stage [70,71]. The frequency of the maintenance is set as a function of the building's service life, the amount of energy required, the transportation methods, the generated volume of waste, and its final disposition. The AIEB reports and calculates the end-of-life effects in two ways. The first deals with current use, including demolition and the transportation of landfill materials. The latter considers the future usage of materials adding Credit for recycling and reusing beyond the buildings life (BBL) [70]. The energy and materials are obtained from demolishing building and transportation to the destined area, and then the impacts are calculated from landfill of waste materials, or their disposal or recycling [72]. The environmental impacts are derived from the building material, demolition energy per unit and an average ratio of waste discharge for recycling or landfill. The recycling or reuse process follows an open-loop recycling scenario that expands into the next use. However, metals follow closed-loop recycling, and the process does not include the next use of the recycled material and its disposal. The analyses in this study follow closed-loop recycling processes. Metals need to be subtracted from the LCI values of the steel scrap, and count as a credit (plus) given to the product system; the net amount of the scrap counts as an avoided burden (minus), which is the recycling of steel scrap to make a new steel. The Worldsteel database and methodology are used to determine the LCI profiles in the software [71]. Since recycling is not well developed and can be expensive, the recycling process results in the production of different materials of lower quality, called downcycling, such as concrete used as filler material and concrete aggregate [73]. This end-of-life stage quantifies the net environmental benefit and loads of all these processes, which subtracts the impacts of the products (secondary material) of recycling [14]. Table 3 lists the total embodied carbon and energy results of each stage and process, whereas Table 4 defines the annual embodied impacts of the 65 -year service life, and Figure 5 provides a graphical presentation of the embodied carbon and energy results of the retrofit scenarios. 
Table 3. Embodied impacts of the scenarios throughout their life span.

\begin{tabular}{|c|c|c|c|c|c|c|c|c|c|c|}
\hline \multirow[t]{2}{*}{ Scenarios } & \multirow{2}{*}{$\begin{array}{l}\text { Impact } \\
\text { Category }\end{array}$} & \multirow[t]{2}{*}{ Unit } & \multicolumn{2}{|l|}{ Site Preparation } & \multicolumn{2}{|c|}{ Manufacturing Process } & \multicolumn{3}{|c|}{ Construction Process } & \multirow[t]{2}{*}{ Total } \\
\hline & & & $\begin{array}{l}\text { Disposal and } \\
\text { Waste Processing }\end{array}$ & Transport & Manufacturing & Transport & $\begin{array}{l}\text { Installation } \\
\text { Process }\end{array}$ & Transport & $\begin{array}{l}\text { Assembly of } \\
\text { Retrofit }\end{array}$ & \\
\hline \multirow[t]{2}{*}{ RC Scenario } & E. Carbon & $\mathrm{Kg} \mathrm{CO}_{2}$ eq & $1.54 \mathrm{E}+01$ & $1.13 \mathrm{E}+01$ & $1.25 \mathrm{E}+04$ & $1.03 \mathrm{E}+02$ & $1.03 \mathrm{E}+03$ & $4.81 \mathrm{E}+02$ & $2.09 \mathrm{E}+00$ & $1.42 \mathrm{E}+04$ \\
\hline & E. Energy & MJ & $2.30 \mathrm{E}+02$ & $1.65 \mathrm{E}+02$ & $1.59 \mathrm{E}+05$ & $1.51 \mathrm{E}+03$ & $1.19 \mathrm{E}+04$ & $6.97 \mathrm{E}+03$ & $2.76 \mathrm{E}+02$ & $1.80 \mathrm{E}+05$ \\
\hline \multirow[t]{3}{*}{ Steel Scenario } & E. Carbon & $\mathrm{Kg} \mathrm{CO}_{2}$ eq & $1.44 \mathrm{E}+01$ & $1.10 \mathrm{E}+01$ & $1.63 \mathrm{E}+04$ & 7.36E-01 & $3.62 \mathrm{E}+02$ & $1.63 \mathrm{E}+02$ & $1.29 \mathrm{E}+01$ & $1.69 \mathrm{E}+04$ \\
\hline & E. Energy & MJ & $2.15 \mathrm{E}+02$ & $1.60 \mathrm{E}+02$ & $2.64 \mathrm{E}+05$ & $1.07 \mathrm{E}+01$ & $5.02 \mathrm{E}+03$ & $2.37 \mathrm{E}+03$ & $1.70 \mathrm{E}+03$ & $2.73 \mathrm{E}+05$ \\
\hline & & & \multicolumn{3}{|l|}{ Usage Stage } & \multicolumn{5}{|l|}{ Usage Stage } \\
\hline Scenarios & $\begin{array}{l}\text { Impact } \\
\text { Category }\end{array}$ & Unit & $\begin{array}{l}\text { Maintenance } \\
\text { Manufacturing }\end{array}$ & Transport & Total & Scenario & $\begin{array}{l}\text { Impact } \\
\text { Category }\end{array}$ & $\begin{array}{l}\text { Maintenance } \\
\text { Manufacturing }\end{array}$ & Transport & Total \\
\hline \multirow[t]{3}{*}{ RC Scenario } & E. Carbon & $\mathrm{Kg} \mathrm{CO}_{2}$ eq & $3.46 \mathrm{E}+02$ & $2.37 \mathrm{E}+01$ & $3.70 \mathrm{E}+02$ & \multirow{2}{*}{ Steel Scenario } & E. Carbon & $2.40 \mathrm{E}+02$ & $1.62 \mathrm{E}+01$ & $2.56 \mathrm{E}+02$ \\
\hline & E. Energy & MJ & $1.85 \mathrm{E}+04$ & $3.44 \mathrm{E}+02$ & $1.88 \mathrm{E}+04$ & & E. Energy & $1.30 \mathrm{E}+04$ & $2.35 \mathrm{E}+02$ & $1.33 \mathrm{E}+04$ \\
\hline & & & \multicolumn{4}{|l|}{ End-of-Life Stage } & & & & \\
\hline Scenarios & $\begin{array}{l}\text { Impact } \\
\text { Category }\end{array}$ & Unit & $\begin{array}{l}\text { Deconstruction, } \\
\text { Demolition, } \\
\text { Disposal and Waste } \\
\text { Processing }\end{array}$ & Transport & BBL Material & Total & & & & \\
\hline \multirow[t]{2}{*}{ RC Scenario } & E. Carbon & $\mathrm{Kg} \mathrm{CO}_{2}$ eq & $5.54 \mathrm{E}+02$ & $2.17 \mathrm{E}+02$ & $2.46 \mathrm{E}+03$ & $3.23 \mathrm{E}+03$ & & & & \\
\hline & E. Energy & MJ & $8.20 \mathrm{E}+03$ & $3.16 \mathrm{E}+03$ & $1.23 \mathrm{E}+04$ & $2.37 \mathrm{E}+04$ & & & & \\
\hline \multirow[t]{2}{*}{ Steel Scenario } & E. Carbon & $\mathrm{Kg} \mathrm{CO}_{2}$ eq & $4.54 \mathrm{E}+02$ & $1.52 \mathrm{E}+01$ & $-2.74 \mathrm{E}+03$ & $-2.27 \mathrm{E}+03$ & & & & \\
\hline & E. Energy & MJ & $6.61 \mathrm{E}+03$ & $2.22 \mathrm{E}+02$ & $-1.26 \mathrm{E}+04$ & $-5.76 \mathrm{E}+03$ & & & & \\
\hline
\end{tabular}


Table 4. Total and annual embodied impacts of the scenarios.

\begin{tabular}{cccccc}
\hline Impact Category & Scenarios & Unit & Total Impacts & Annual Impacts & Relative Comparison \\
\hline \multirow{2}{*}{ Embodied Carbon } & RC Scenario & $\mathrm{Kg} \mathrm{CO}_{2}$ eq & $1.78 \mathrm{E}+04$ & $2.74 \mathrm{E}+02$ & $20 \%$ Increase \\
\cline { 2 - 6 } & Steel Scenario & $\mathrm{Kg} \mathrm{CO}_{2}$ eq & $1.49 \mathrm{E}+04$ & $2.29 \mathrm{E}+02$ & $16 \%$ Reduction \\
\hline \multirow{2}{*}{ Embodied Energy } & RC Scenario & $\mathrm{MJ}$ & $2.23 \mathrm{E}+05$ & $3.42 \mathrm{E}+03$ & $20 \%$ Reduction \\
\cline { 2 - 6 } & Steel Scenario & $\mathrm{MJ}$ & $2.81 \mathrm{E}+05$ & $4.32 \mathrm{E}+03$ & $26 \%$ Increase \\
\hline
\end{tabular}
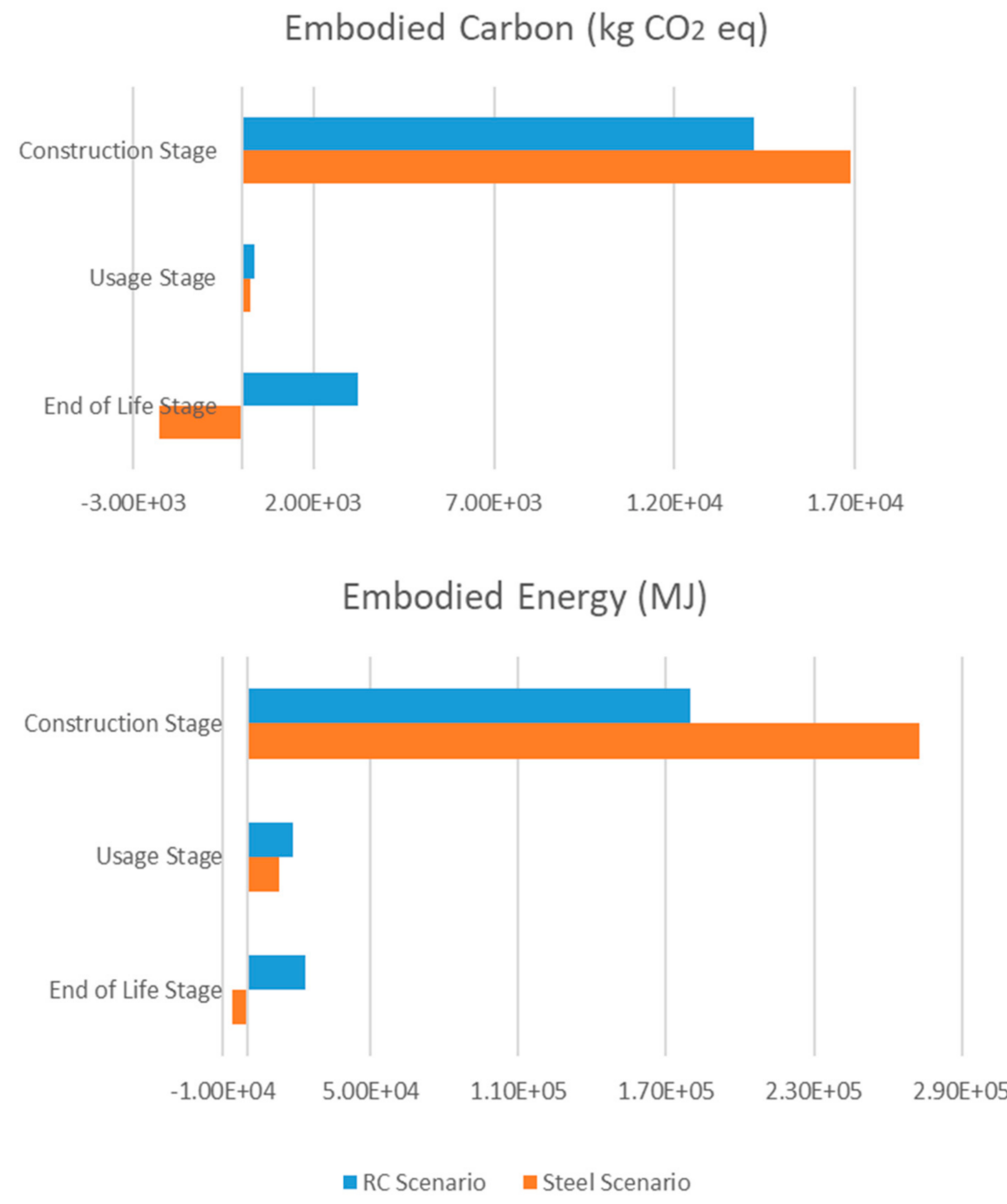

Figure 5. Comparative embodied carbon and energy graphs of the scenarios.

Figure 5 shows a difference between the selected retrofit techniques of about $16 \%$ and $35 \%$ in embodied carbon and energy, respectively, during the construction stage, RC being more efficient. In contrast, the steel scenario revealed more sustainable performances during usage and end-of-life. According to these results, the steel scenario embodies $30 \%$ less energy and carbon than RC during the usage stage. Moreover, during the end-of-life stage, the steel scenario outperforms RC by $170 \%$ and $125 \%$ for embodied carbon and energy, respectively. The negative values in the results show the avoided burdens of recycling steel. Regarding the RC scenario, it involves more solid waste for using as a landfill material than the steel scenario due to the high amount of concrete used. Regarding annual impacts, the steel scenario involved $26 \%$ more annual embodied energy than the 
RC scenario. Conversely, a 16\% decrease was recorded in embodied carbon emissions from the steel scenario, as presented in Table 4 . Therefore, the building's LCA stages and service life have a meaningful impact on a building's life cycle's footprint.

Figure 6 summarizes the environmental impacts associated with retrofitting chronologically. The horizontal axis of this figure discretizes five-year blocks considering the above-mentioned embodied impacts but omitting any future changes. From these results, one can infer that embodied carbon due to maintenance makes a minor contribution compared to construction and end-of-life stages.

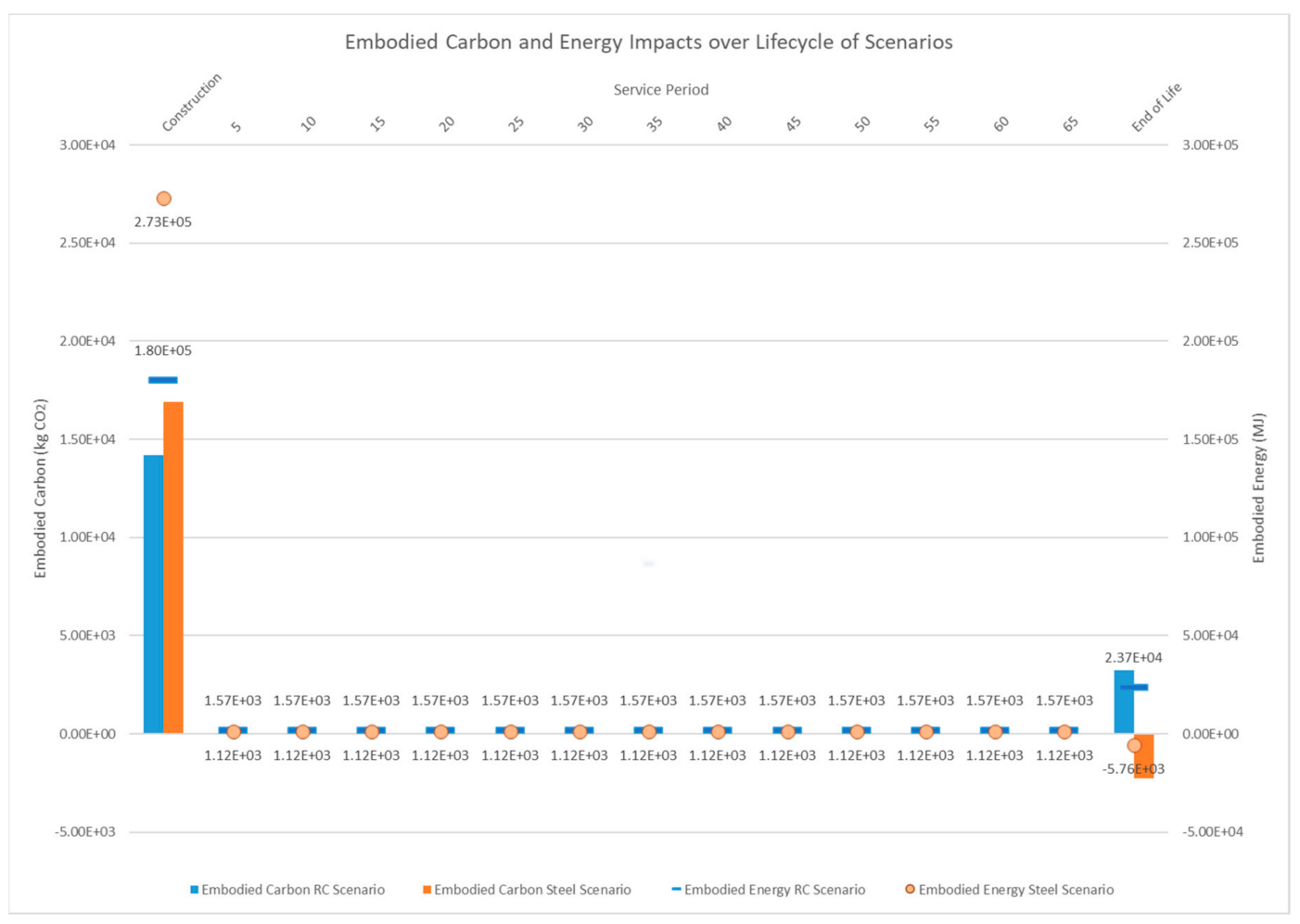

Figure 6. Embodied impacts of the retrofits during the building's life cycle.

\subsubsection{Interpretation}

The results above show that the manufacturing process induces the most significant environmental impacts, with up to $88 \%$ of the total impacts during construction of the RC scenario, whereas the manufacturing process for the steel scenario exceeds $96 \%$. Vitiello et al. [55] pointed out that during the construction of RC jacketing, environmental impacts occur mainly during material manufacturing, and these constitute approximately $50 \%$ of the impacts from the construction stage. The manufacturing process also dominates the steel scenario as the industrial processes consume much energy. Transportation also causes energy consumption, but in a lower scale, hence not affecting the total results.

As discussed above, the RC scenario is more efficient during the construction stage, while steel performs better during usage and end-of-life stages. The existence of recyclable materials contributes to these differences. Furthermore, the benefit of reusing materials is also observed in the annual impacts, where $16 \%$ of the embodied carbon is reduced when implementing the steel scenario. However, annual embodied energy increased by $26 \%$ because of the high use of energy associated with steel production. Similar embodied energy results are reported by Feese, Li and Bulleit [38], wherein the energy quantified for repair reached 270,924 MJ; in that case, they were using probability-based pre-code design recommendations for a concrete building (low-rise office with 60 years' service life) damaged during the Northridge earthquake. Our case study is located in Turkey, where the total embodied energy was found to be $222,500 \mathrm{MJ}$ and 280,540 MJ for the RC and steel retrofit scenarios, respectively. Similarly, in the study by Feese, Li and Bulleit [38], the 
annual energy consumption was $4103 \mathrm{MJ}$ for the repair of a moderately designed concrete building, which compares well with the figures estimated in this study, namely, $3423 \mathrm{MJ}$ and $4316 \mathrm{MJ}$ for the RC and steel scenarios, respectively. The case reported in [38] relates to a 6.7 magnitude earthquake that hit Los Angles in 1994. Notwithstanding that the 1994 earthquake was of lower magnitude than the one for our scenario, the results fall within a reasonable range of difference, which suggests these could be representative of concrete buildings.

On the other hand, we saw before that the steel scenario imposes larger impacts during manufacturing, partly due to using resources such as dolomite, ferrous scrap, lignite, and natural gas. Nonetheless, Table 2 suggests that steel retrofitting techniques do not require the highest levels of resource across the board, which gives a point of reference for industrialists that wish to further optimize the use of resources and energy consumption. According to the results, if the steel scenario is implemented, about 51 tons of coarse aggregate, $790 \mathrm{~L}$ of crude oil, $537 \mathrm{~kg}$ of iron ore, 9 tons of limestone, 37,500 L of water, $973 \mathrm{~kg}$ of wood fiber, and much besides can be saved. Furthermore, 3 tons less embodied $\mathrm{CO}_{2}$ (eq) can be emitted.

\section{End-of-Life Procedure}

The end-of-life procedure was used here to compare the environmental performances of retrofitted and non-retrofitted scenarios of a medium-damaged building. The built-up scenarios involve (i) strengthening the vulnerable building and (ii) demolishing the existing one and building a new one.

\subsection{Pre-LCA of the Medium-Damaged Building}

\subsubsection{As-Built Information}

The building is located in Mexico City, and experienced two major events in 1957 and 1985 (MW = 8.1). It is a hospital complex including four blocks. No original drawings were available, although qualitative information could be obtained from final year projects reported by Martinez Vazquez [74] and Almanza [75]. The RC original building had masonry walls sub-dividing space, although the resisting mechanisms were provided by rigid frames cast monolithically with slabs. These masonry walls did not have a structural function, but some concrete walls spread through floor levels provided additional shear capacity. The four building blocks forming the complex have constructive joints at their intersection, which made them work independently before any type of load.

The initial inspection of the structure found it was in good conditions, partly due to the fact that, after the seismic event in 1957, the main RC elements were upgraded. Geotechnical reports on the substructure and subsoil disclosed material properties. In the 1990s, the hospital went through a major upgrade due to changes in building regulations after the 1985 earthquake [76]. The building withstood lateral forces that were well above the limit state of the old regulation; however, leaving it as it was could result in further damage or collapse in future earthquake events. The building is therefore classified as vulnerable.

The building's age was 46 at the time of the retrofit. Noting that hospital buildings in Mexico are designed for a service life of at least 60 years, and given its relatively good state, the authorities decided to extend its lifespan through retrofit. For this building, it was assumed that the reinforcement would increase the building's service life to another 40 years after the retrofit. The purpose of laying out these assumptions is to reflect the differences between the extended and new service periods of these two scenarios in terms of their LCA performance.

\subsubsection{Assessment of Structural Capacity}

The building is located within Zone II (transition) according to the seismic and geotechnical zoning of the Mexican regulations. The dynamic analysis, therefore, used the corresponding design spectrum to design the retrofit [77]. According to national codes, the maximum allowable displacement is 0.006 times the height of the building. The maximum permissible displacement value was obtained as $19.32 \mathrm{~cm}$ when considering the masonry 
walls. However, the original structure's static and dynamic analysis showed that the maximum displacement exceeded this limit. The maximum displacement was obtained as $32.3 \mathrm{~cm}$ and $38.2 \mathrm{~cm}$ via static and dynamic analysis, respectively. Therefore, the lateral rigidity of the structure needed to increase.

\subsubsection{Selection of Structural Interventions}

The retrofit project re-configured spaces to provide better hospital services, in addition to complying with the relevant limit states as per the new regulation. The retrofit consisted of external trusses attached to the mainframes through bolted connections. Each of these trusses has its own foundation system formed with piles confined with an RC arrangement at their top, where the truss structure is connected.

The bolted connections amongst truss elements had a certain frictional capacity, which made them displace once the primary force levels were exceeded. This type of connection enables joints to dissipate energy during seismic action without damaging the building and its functionality. All stories across the four building blocks were further strengthened with internal diagonal steel elements linked to the original structure. This inner retrofit is balanced with the external trusses referred to above, hence inducing symmetric stiffness to mitigate torsional effects.

In this study, the first scenario consists of retrofitting the vulnerable building as outlined above. A second (hypothetical) scenario-referred to as non-retrofitted—consists of demolishing the vulnerable building to construct a new one. For simplicity, it was assumed that the new building would have the same architecture as the existing one. Figure 7 presents the original building and including retrofit elements.

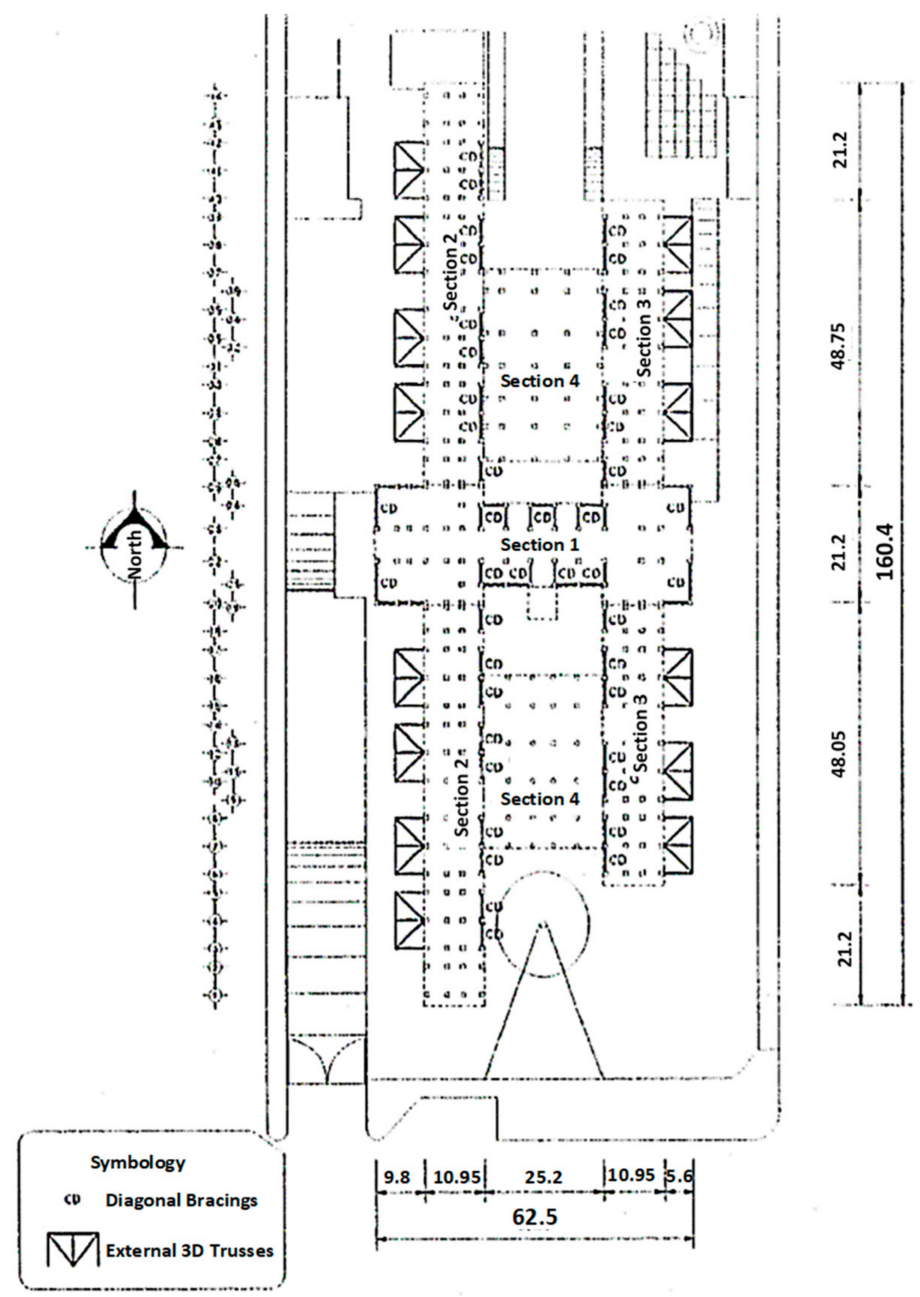

Figure 7. Distribution and placing of reinforced elements for the original building in the first scenario. 


\subsection{LCA of the Medium-Damaged Building}

This process includes the life cycle environmental assessment of the retrofitted scenario versus the non-retrofitted scenario.

\subsubsection{Goal and Scope}

The performance comparison of selected scenarios is aimed at their life cycle impacts, and the scope of the analysis includes structural retrofitting and new building construction.

\subsubsection{LCI}

The following analysis adopted the same methods and processes for determining sustainability impacts as those reported in the previous case study. The two scenarios considered in the analysis are depicted in the flow diagram Figure 8, whereas Figure 9 illustrates typical connections between the steel retrofit and RC frames. Activities related to maintenance were considered, given the amount of steel retrofit directly exposed to the environment. Furthermore, the replacement of fixings and windows was quantified for the total 60-year service period of the new building. Finally, end-of-life stages included demolition works associated with either scenario.

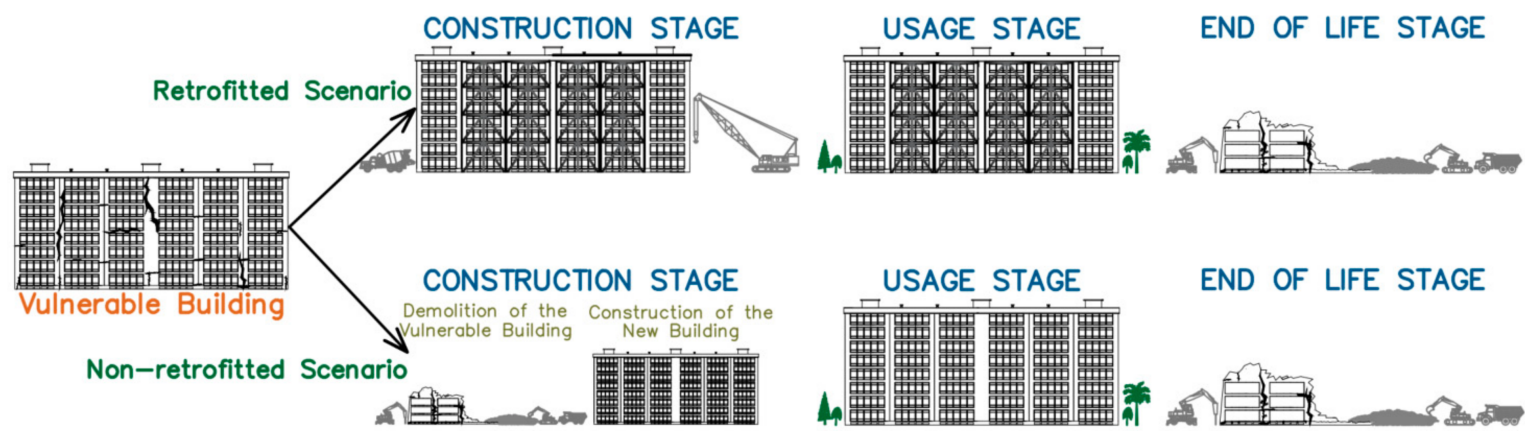

Figure 8. Schematic representation of a medium-damaged building's LCA stages over the selected scenarios.
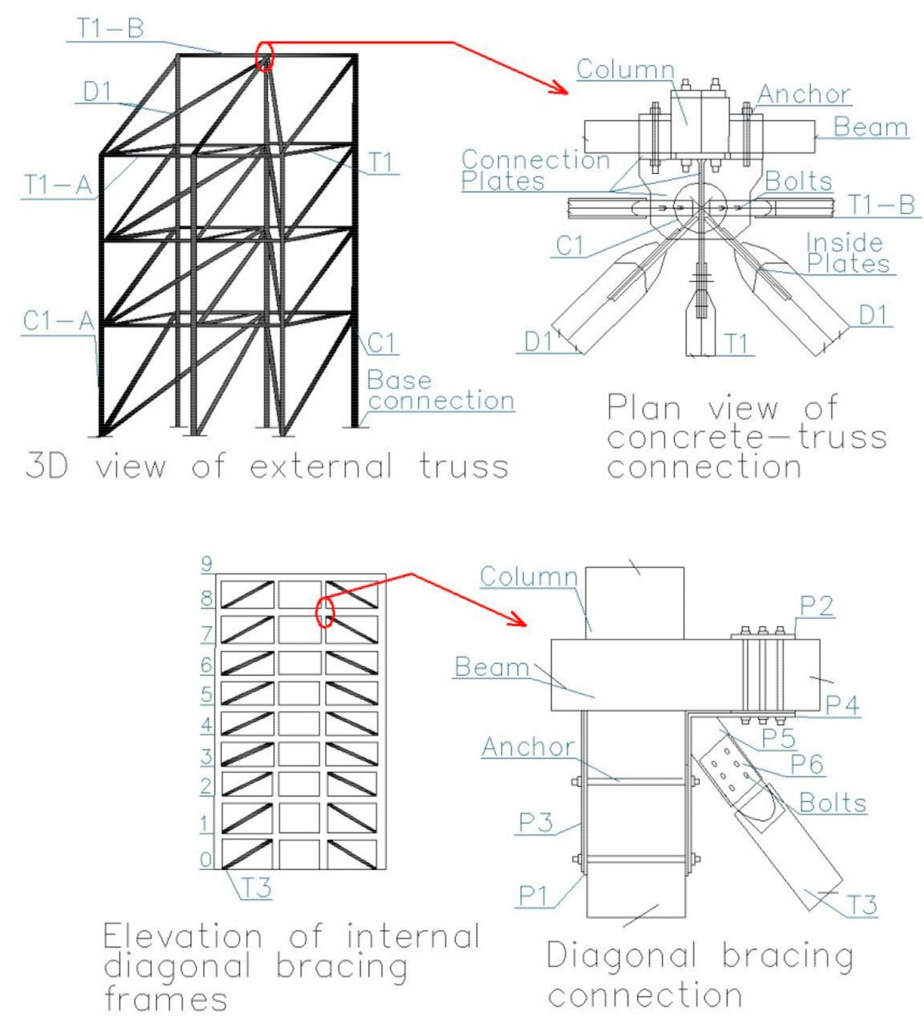

Figure 9. The $3 \mathrm{D}$ and diagonal joints of plates and tubes for the first scenario. 
To work out the quantification of sustainability parameters, the original building was modeled in the AIEB tool to generate the corresponding BOM. In that platform, retrofit materials were added as extra materials to simulate structural intervention. On the other hand, the new building for the second scenario was also modeled with AIEB considering material types corresponding to the original building, and upgraded designs according to structural features of hospital buildings in Mexico [78].

\subsubsection{LCIA}

The system boundaries in AIEB were also applied for this medium-damaged building. The case study also included the operation energy and carbon related to different service periods of 40 to 60 years.

\section{Resource Use Analysis Results}

Table 5 lists the resources that directly affect the embodied impacts of interventions; hence the operational energy, site preparation and assembly of the retrofit are not included in the list. In this analysis, the main contribution is identified during the construction stages, whereas the usage and end-of-life stages have low impact. The second scenario (hypothetical demolition and new building) would have induced more resource consumption across the board.

Table 5. The resource use of both scenarios.

\begin{tabular}{llll}
\hline \multirow{2}{*}{ Material } & Unit & Resource Use & \\
\cline { 3 - 4 } & & First Scenario & Second Scenario \\
\hline Aluminium scrap & $\mathrm{kg}$ & $7.36 \mathrm{E}+03$ & $2.47 \mathrm{E}+04$ \\
Ash & $\mathrm{kg}$ & $3.63 \mathrm{E}+01$ & 0 \\
Bauxite & $\mathrm{kg}$ & $-2.12 \mathrm{E}+04$ & $-6.02 \mathrm{E}+04$ \\
Carbon dioxide, in air & $\mathrm{kg}$ & $1.91 \mathrm{E}+04$ & $6.24 \mathrm{E}+04$ \\
Clay and shale & $\mathrm{kg}$ & $1.50 \mathrm{E}+04$ & $4.47 \mathrm{E}+05$ \\
Coal & $\mathrm{kg}$ & $8.88 \mathrm{E}+05$ & $3.04 \mathrm{E}+06$ \\
Coarse aggregate & $\mathrm{kg}$ & $2.13 \mathrm{E}+06$ & $7.35 \mathrm{E}+07$ \\
Crude oil & $\mathrm{L}$ & $4.71 \mathrm{E}+05$ & $2.08 \mathrm{E}+06$ \\
Crude oil as feedstock & $\mathrm{L}$ & $3.05 \mathrm{E}+04$ & $4.73 \mathrm{E}+04$ \\
Dolomite & $\mathrm{kg}$ & $9.77 \mathrm{E}+04$ & $2.14 \mathrm{E}+05$ \\
Ferrous scrap & $\mathrm{kg}$ & $9.54 \mathrm{E}+05$ & $2.89 \mathrm{E}+06$ \\
Gypsum (natural) & $\mathrm{kg}$ & $1.57 \mathrm{E}+04$ & $4.63 \mathrm{E}+05$ \\
Gypsum (synthetic) & $\mathrm{kg}$ & $6.67 \mathrm{E}+01$ & $1.03 \mathrm{E}+03$ \\
Iron ore & $\mathrm{kg}$ & $1.30 \mathrm{E}+06$ & $2.28 \mathrm{E}+06$ \\
Lignite & $\mathrm{kg}$ & $-2.64 \mathrm{E}+04$ & $-5.63 \mathrm{E}+04$ \\
Limestone & $\mathrm{kg}$ & $5.52 \mathrm{E}+05$ & $1.54 \mathrm{E}+07$ \\
Natural gas & $\mathrm{m}$ & $1.53 \mathrm{E}+05$ & $6.73 \mathrm{E}+05$ \\
Natural gas as feedstock & $\mathrm{m}$ & $4.09 \mathrm{E}+04$ & $6.34 \mathrm{E}+04$ \\
Other & $\mathrm{kg}$ & $8.94 \mathrm{E}+04$ & $8.31 \mathrm{E}+05$ \\
Peat & $\mathrm{kg}$ & $3.83 \mathrm{E}+00$ & $1.25 \mathrm{E}+02$ \\
Potash & $\mathrm{kg}$ & $2.94 \mathrm{E}+02$ & $1.12 \mathrm{E}+03$ \\
Sand & $\mathrm{kg}$ & $-2.13 \mathrm{E}+02$ & $-5.48 \mathrm{E}+02$ \\
Tin ore & $\mathrm{kg}$ & $3.92 \mathrm{E}-04$ & $1.19 \mathrm{E}-02$ \\
Uranium & $\mathrm{kg}$ & $1.25 \mathrm{E}+00$ & $1.41 \mathrm{E}+01$ \\
Water & $\mathrm{L}$ & $2.70 \mathrm{E}+07$ & $1.72 \mathrm{E}+08$ \\
Wood fiber & $\mathrm{kg}$ & $1.23 \mathrm{E}+04$ & $3.65 \mathrm{E}+05$ \\
\hline & & &
\end{tabular}

\section{Embodied Carbon and Energy Analysis Results}

In the present case study, $350 \mathrm{kWh} / \mathrm{m}^{2}$ was assumed to be the annual energy consumption of a regular hospital building when calculating its operational impacts. The value was determined according to $[79,80]$ considering bed number, floor area and climate zone. Table 6 presents the total embodied and operational impact results for each stage and process, whereas Table 7 lists the annual impacts of the 40- and 60- year service periods. 
In this set of results, operational carbon and energy only refer to the usage stage. The operational impacts reported for the first scenario are 33\% lower, but are proportional to the service period identified for the retrofit building ( 40 years). Table 7 also shows that the operational impacts surpassed embodied impacts; therefore, the operational phase of the building is excluded in the life cycle embodied impacts, as seen in Figure 10. Of the embodied impacts, $52 \%$ and $87 \%$ were caused by the construction stage for the first and second scenarios, respectively. It is noticeable in Figure 10 that embodied carbon in the first scenario is $90 \%$ lower than its equivalent amount in the second scenario during the construction stage during which most of the impact takes place. This relative difference was also present during the usage and end-of-life stages, although at a lower scale. The reductions seen in those cases are $58 \%$ and $8 \%$, respectively. Embodied energy also shows a similar pattern, with $84 \%, 44 \%$, and $3 \%$ decreases for the first scenario's construction, usage, and end-of-life stages, respectively.
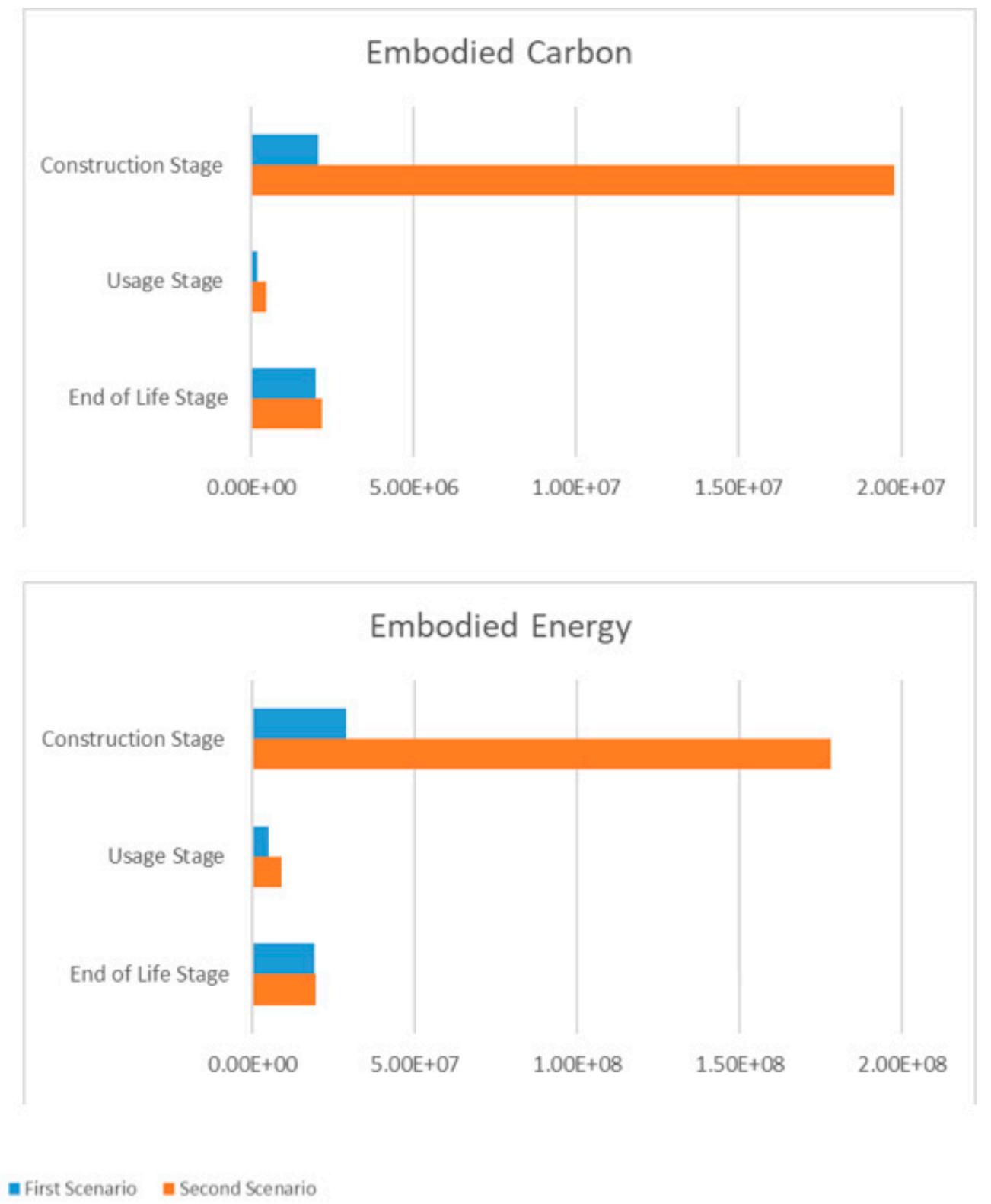

Figure 10. Life cycle embodied carbon and energy impacts of both scenarios. 
Table 6. Embodied and operational impacts of the scenarios during their service life.

\begin{tabular}{|c|c|c|c|c|c|c|c|c|c|c|c|}
\hline \multirow[t]{2}{*}{ Scenarios } & \multirow{2}{*}{$\begin{array}{l}\text { Impact } \\
\text { Category }\end{array}$} & \multirow[t]{2}{*}{ Unit } & \multicolumn{3}{|l|}{ Site Preparation } & \multicolumn{2}{|c|}{ Manufacturing of Retrofit } & \multicolumn{3}{|c|}{ Construction of Retrofit } & \multirow[t]{2}{*}{ Total } \\
\hline & & & $\begin{array}{l}\text { Disposal and } \\
\text { Waste Processing }\end{array}$ & Transport & & Manufacturing & Transport & $\begin{array}{l}\text { Installation } \\
\text { Process }\end{array}$ & Transport & $\begin{array}{l}\text { Assembly of } \\
\text { Retrofit }\end{array}$ & \\
\hline \multirow{3}{*}{$\begin{array}{l}\text { First } \\
\text { Scenario }\end{array}$} & E. Carbon & $\mathrm{Kg} \mathrm{CO}_{2}$ eq & $1.95 \mathrm{E}+02$ & $8.17 \mathrm{E}+01$ & & $1.74 \mathrm{E}+06$ & $2.87 \mathrm{E}+03$ & $6.25 \mathrm{E}+04$ & $2.30 \mathrm{E}+05$ & $7.14 \mathrm{E}+03$ & $2.04 \mathrm{E}+06$ \\
\hline & E. Energy & MJ & $2.91 \mathrm{E}+03$ & $1.19 \mathrm{E}+03$ & & $2.49 \mathrm{E}+07$ & $4.19 \mathrm{E}+04$ & $7.80 \mathrm{E}+05$ & $3.27 \mathrm{E}+06$ & $1.23 \mathrm{E}+05$ & $2.91 \mathrm{E}+07$ \\
\hline & & & \multicolumn{3}{|c|}{ Demolition of the Original Building } & \multicolumn{2}{|c|}{$\begin{array}{l}\text { Manufacturing of the New } \\
\text { Building }\end{array}$} & \multicolumn{3}{|c|}{ Construction of the New Building } & Total \\
\hline \multirow{4}{*}{$\begin{array}{l}\text { Second } \\
\text { Scenario }\end{array}$} & E. Carbon & $\mathrm{Kg} \mathrm{CO}_{2}$ eq & $6.62 \mathrm{E}+05$ & $2.63 \mathrm{E}+05$ & $1.10 \mathrm{E}+06$ & $1.49 \mathrm{E}+07$ & $1.01 \mathrm{E}+05$ & $1.28 \mathrm{E}+06$ & $1.48 \mathrm{E}+06$ & & $1.98 \mathrm{E}+07$ \\
\hline & E. Energy & MJ & $9.83 \mathrm{E}+06$ & $3.83 \mathrm{E}+06$ & $4.90 \mathrm{E}+06$ & $1.23 \mathrm{E}+08$ & $1.47 \mathrm{E}+06$ & $1.37 \mathrm{E}+07$ & $2.14 \mathrm{E}+07$ & & $1.78 \mathrm{E}+08$ \\
\hline & & & \multicolumn{6}{|l|}{ Usage Stage } & & & \\
\hline & & & $\begin{array}{l}\text { Maintenance } \\
\text { Manufacturing }\end{array}$ & Transport & & $\begin{array}{l}\text { Maintenance } \\
\text { Process }\end{array}$ & $\begin{array}{l}\text { Operational } \\
\text { Energy Use }\end{array}$ & Total & & & \\
\hline $\begin{array}{l}\text { First } \\
\text { Scenario }\end{array}$ & E. Carbon & $\mathrm{Kg} \mathrm{CO}_{2}$ eq & $1.59 \mathrm{E}+05$ & $2.81 \mathrm{E}+04$ & & $1.24 \mathrm{E}+03$ & $2.80 \mathrm{E}+08$ & $2.80 \mathrm{E}+08$ & & & \\
\hline \multirow{2}{*}{$\begin{array}{l}\text { Second } \\
\text { Scenario }\end{array}$} & E. Carbon & $\mathrm{Kg} \mathrm{CO}_{2} \mathrm{eq}$ & $3.94 \mathrm{E}+05$ & $5.68 \mathrm{E}+04$ & & - & $4.19 \mathrm{E}+08$ & $4.20 \mathrm{E}+08$ & & & \\
\hline & E. Energy & MJ & $8.40 \mathrm{E}+06$ & $8.24 \mathrm{E}+05$ & & - & $7.78 \mathrm{E}+09$ & $7.79 \mathrm{E}+09$ & & & \\
\hline
\end{tabular}


Continuation of Table 6 Embodied and operational impacts of the scenarios during their service life.

\begin{tabular}{lllllll}
\hline Scenarios & Impact Category & Unit & End-of-Life Stage & & Total \\
\cline { 3 - 8 } & & & $\begin{array}{l}\text { Deconstruction, } \\
\text { Demolition, Disposal } \\
\text { and Waste Processing }\end{array}$ & Transport & BBL Material \\
\hline \multirow{2}{*}{ First Scenario } & E. Carbon & $\mathrm{Kg} \mathrm{CO}_{2}$ eq & $7.15 \mathrm{E}+05$ & $2.72 \mathrm{E}+05$ & $9.92 \mathrm{E}+05$ & $1.98 \mathrm{E}+06$ \\
\cline { 2 - 8 } & E. Energy & $\mathrm{MJ}$ & $1.06 \mathrm{E}+07$ & $3.96 \mathrm{E}+06$ & $4.39 \mathrm{E}+06$ & $1.90 \mathrm{E}+07$ \\
\hline \multirow{2}{*}{ Second Scenario } & E. Carbon & $\mathrm{Kg} \mathrm{CO}$ eq & $7.26 \mathrm{E}+05$ & $2.88 \mathrm{E}+05$ & $1.15 \mathrm{E}+06$ & $2.16 \mathrm{E}+06$ \\
\cline { 2 - 9 } & E. Energy & $\mathrm{MJ}$ & $1.08 \mathrm{E}+07$ & $4.20 \mathrm{E}+06$ & $4.63 \mathrm{E}+06$ & $1.96 \mathrm{E}+07$ \\
\hline
\end{tabular}

Table 7. Total and annual embodied and operational impacts of the scenarios.

\begin{tabular}{llllll}
\hline Impact Category & Scenarios & Unit & Total Impacts & Annual Impacts & Relative Comparison \\
\hline \multirow{2}{*}{ Embodied Carbon } & First Scenario & $\mathrm{Kg} \mathrm{CO}_{2} \mathrm{eq}$ & $4.21 \mathrm{E}+06$ & $1.05 \mathrm{E}+05$ & $72 \%$ Reduction \\
\cline { 2 - 6 } & Second Scenario & $\mathrm{Kg} \mathrm{CO}_{2} \mathrm{eq}$ & $2.24 \mathrm{E}+07$ & $3.73 \mathrm{E}+05$ & $255 \%$ Increase \\
\hline \multirow{2}{*}{ Operational Carbon } & First Scenario & $\mathrm{Kg} \mathrm{CO}_{2} \mathrm{eq}$ & $2.80 \mathrm{E}+08$ & $7.00 \mathrm{E}+06$ & $0.2 \%$ Increase \\
\cline { 2 - 6 } & Second Scenario & $\mathrm{Kg} \mathrm{CO} 2 \mathrm{eq}$ & $4.19 \mathrm{E}+08$ & $6.98 \mathrm{E}+06$ & $0.3 \%$ Reduction \\
\hline \multirow{2}{*}{ Embodied Energy } & First Scenario & $\mathrm{MJ}$ & $5.33 \mathrm{E}+07$ & $1.33 \mathrm{E}+06$ & $61 \%$ Reduction \\
\cline { 2 - 6 } & Second Scenario & $\mathrm{MJ}$ & $2.07 \mathrm{E}+08$ & $3.45 \mathrm{E}+06$ & $160 \%$ Increase \\
\hline \multirow{2}{*}{ Operational Energy } & First Scenario & $\mathrm{MJ}$ & $5.19 \mathrm{E}+09$ & $1.30 \mathrm{E}+08$ & $0.06 \%$ Increase \\
\cline { 2 - 6 } & Second Scenario & $\mathrm{MJ}$ & $7.78 \mathrm{E}+09$ & $1.30 \mathrm{E}+08$ & $0.06 \%$ Reduction \\
\hline
\end{tabular}

According to the results, the whole life cycle's embodied carbon and energy constitute less than $1 \%$ of the combined (embodied and operational) impacts of the first scenario, but these constitute up to $5 \%$ and $3 \%$, respectively, in the second scenario. Table 7 also reveals a drop of $72 \%$ and $61 \%$ in annual embodied carbon and energy, respectively, with respect to their total amounts. In contrast, operational energy and carbon did not change significantly. There, we see a $0.2 \%$ and $0.06 \%$ increase in the first scenario's annual impacts because of the shorter service period.

Figure 11 shows changes between embodied and operational impacts for each scenario over their service periods. As pointed out before, embodied impacts make a minor contribution to emissions compared to the operational stage, whereas the contribution of periodic maintenance (every five years) is insignificant, and thus not seen in the figures. Embodied carbon and energy comprise $0.07 \%$ and $0.1 \%$, respectively, of the total impacts during the same period of use.

\subsubsection{Interpretation}

In the second scenario, the manufacturing process impacts dominate over the construction stage due to the material needed to build a new structure. Similarly, manufacturing caused significant carbon emissions in the first scenario, contributing $85 \%$ of the total emissions during the construction stage. This is consistent with the report by Wei et al. [31], who estimated that manufacturing materials for a retrofit construction generate up to $84 \%$ of the $\mathrm{CO}_{2}$ emissions. On the other hand, retrofitting constituted approximately $50 \%$ of the first scenario's total environmental impact throughout its life cycle. When comparing the impacts of only retrofitting with the new building, while retrofitting made only $10 \%$ of the impact of new building construction (including demolition of the existing building), it only accounted for $9 \%$ of the second scenario's total embodied carbon. In the study by Comber and Poland [41], a similar conclusion about environmental impacts was derived after upgrading a medical building, which reduced its total emissions to around $9 \%$. 

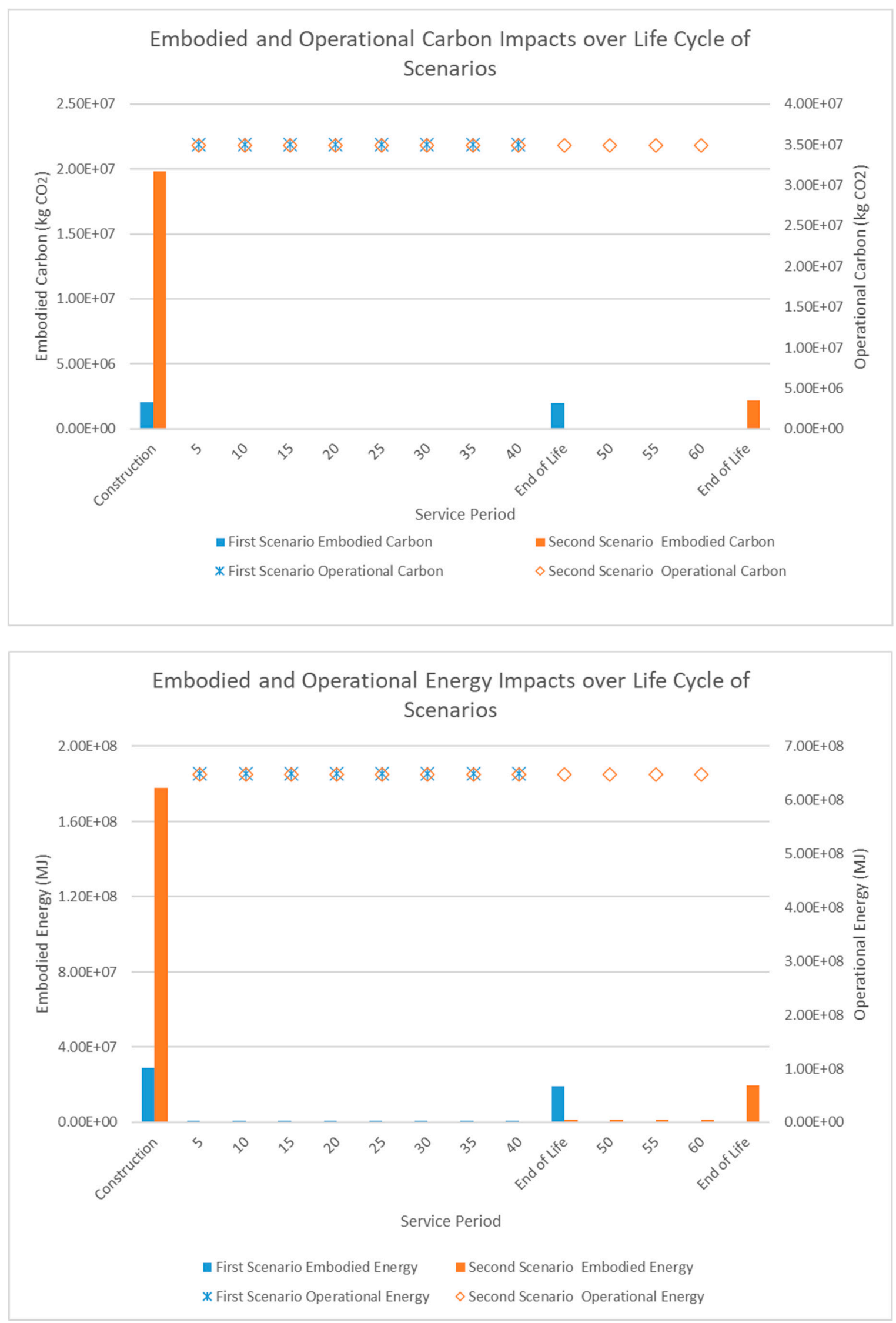

Figure 11. Embodied and operational impacts of both scenarios during their service period. 
During the usage stage, it is evident that replacement activities, maintenance, and operation have a larger impact under the second scenario due to the longer service period. The analysis results also highlight that embodied impacts are much lower compared to operational impacts. Once again, we see reductions in embodied carbon and energy of around $72 \%$ and $61 \%$ annually through implementing retrofit as opposed to the demolition of the vulnerable structure.

Regarding demolition, the second scenario had a higher environmental impact than the first scenario, and the main effects of building demolition in the first scenario stemmed from the existing building. Retrofit produced only an average of $6 \%$ of the total environmental impacts of the first scenario.

During the BBL process, the benefit of recycling materials can be seen. The first scenario had lower environmental impacts than the second. This is mostly because of the higher recycling potential of retrofitting materials. As seen in the resource use results, the second scenario involves a higher avoided burden of recycling, shown as a minus, and this reduces the new building's environmental impacts slightly compared to the original building. In addition to that, the second scenario's resource use turned out to be relatively high, and most of this amount was due to the construction stage. Embodied impacts have also been observed, which affected various natural resources and are not limited to energy resources as operational impacts. Hence, a high amount of resource consumption can be avoided if the retrofitted scenario is applied; for instance, about 71,370 tons of coarse aggregate, 14,848 tons of limestone, $520,000 \mathrm{~m}^{3}$ of natural gas, 353 tons of wood fiber and 145 million L of water usage can be saved. Additionally, 157,940 tons $\mathrm{CO}_{2}$ less embodied emissions can be emitted and 2,739,500 GJ less embodied energy consumed.

Overall, structural retrofitting activities caused $48 \%$ of total embodied carbon impacts; this result is exactly the same as that derived from Hossain and Gencturk's [48] case study of a low-cost, low-performance building. Embodied carbon and energy constitute 5\% and $3 \%$ of total operational and embodied impacts in the second scenario, while they share only $1 \%$ in the first scenario. The first scenario's total embodied carbon impacts are only $19 \%$ of the second scenario's total impacts (5 times lower), and the impact from the retrofit construction is only one-tenth of that of the new building construction. Therefore, the retrofitting of buildings provides a great advantage in reducing emissions from new building construction.

\section{Conclusions}

The concept of structural intervention in vulnerable buildings is here further scrutinized and incorporated into key sustainability metrics. Therefore, an integrated sustainable structural intervention (SSIM) method was proposed to consider the life cycle environmental impacts of buildings, scales of damage, service life, and variability of local conditions regarding structural safety. The study introduced a comprehensive and systematic framework developed in Pre-LCA and LCA stages, considering several design options of retrofit scenarios and retrofit-versus-non-retrofit scenarios of vulnerable buildings. It also addressed the resource use of selected scenarios beyond environmental impacts, including the extended service lives of buildings after retrofitting. Then, the method was applied to low- and medium-damaged buildings.

According to the results, the steel scenario was the most beneficial option, since it leads to less resource use and embodied carbon emissions than the RC scenario. Regarding the second case study, retrofitting according to the proposed method provided an advantage by avoiding constructing a new building, which permits less embodied impacts and lower resource use. While the lower rate of resource use helped to reduce the embodied impacts during construction and use, recyclable materials also provided an advantage in terms of the reuse of resources at the end-of-life stage. The service period significantly influenced the annual environmental impacts, making notable changes in life cycle assessments. Embodied impacts are a minor part of the building life cycle's environmental impacts; however, it has been observed that this impact can be further reduced with a 
sustainable method. In addition to that, reducing embodied impacts help protect several resources in nature. Therefore, embodied impacts are also unavoidable in the realization of genuine zero-carbon buildings. It was also found that each strengthening technique should undergo project-based evaluation due to the differences in their designs according to the vulnerability of the building.

The proposed method provides a practical and viable framework for improving vulnerable buildings' sustainable performance by using the well-explained and defined steps of an integrated LCA procedure. The results of this study can also contribute to the historical loss data of environmental impacts associated with the retrofitting of vulnerable buildings for selected regions, as real case studies were used without using probabilistic loss estimation. The further refinement of such integrated methods would help in improving the life cycle sustainability and resilience of buildings by steering countries towards better approaches; eventually, it will help the sustainable transformation of cities.

Author Contributions: All authors have contributed to the work reported. Responsible for the abstract, introduction, methodology, case study analysis and conclusions was F.S.K.; writing —original draft preparation, F.S.K.; supervision, revision, editing and proofreading, P.M.-V. and C.B. All authors have read and agreed to the published version of the manuscript.

Funding: The first author would also like to thank her sponsor, the Ministry of National Education, Republic of Turkey, for funding her doctoral studies at the University of Birmingham under the scholarship of Higher Education.

Data Availability Statement: Not applicable.

Conflicts of Interest: No potential conflict of interest was reported by the authors. The funders had no role in the design of the study; in the collection, analyses, or interpretation of data; in the writing of the manuscript or in the decision to publish the results.

\section{References}

1. Coburn, A.; Sspence, R.J.S.; Pomonis, A. Vulnerability and Risk Assessment, 2nd ed.; Disaster Management Training Programme; UNDP/DHA: Geneva, Switzerland, 1994.

2. Pîrvănus, A.-M. Aspects on the Measures Applied at National Level for the Safety of Vulnerable Building Stock in Bucharest Municipality. Constructii 2020, 21, 40-47.

3. EM-DAT. The Emergency Events Database; EM-DAT: Brussels, Belgium, 2019.

4. Ritchie, H. Natural Disasters. Available online: https:/ / ourworldindata.org/natural-disasters (accessed on 10 November 2020).

5. Wei, H.-H.; Shohet, I.M.; Skibniewski, M.J.; Shapira, S.; Yao, X. Assessing the lifecycle sustainability costs and benefits of seismic mitigation designs for buildings. J. Archit. Eng. 2016, 22, 4015011. [CrossRef]

6. Bhattacharya, S.; Nayak, S.; Dutta, S.C. A critical review of retrofitting methods for unreinforced masonry structures. Int. J. Disaster Risk Reduct. 2014, 7, 51-67. [CrossRef]

7. Tucker, B.E. Reducing Earthquake Risk. Science 2013, 341, 1070-1072. [CrossRef] [PubMed]

8. Bilham, R. The seismic future of cities. Bull. Earthq. Eng. 2009, 7, 839-887. [CrossRef]

9. IEA International Energy Agency. Energy Efficiency: Buildings. Available online: https://www.iea.org/topics/energyefficiency/ buildings/ (accessed on 7 September 2019).

10. C40 Cities. The Net Zero Carbon Buildings Declaration. Available online: https://www.c40.org/other/net-zero-carbonbuildings-declaration (accessed on 7 November 2020).

11. UN. Emissions Gap Report 2019; UN: New York, NY, USA, 2019.

12. O'Connor, J. What Can We Do about Embodied Carbon? Canadian Architect: Toronto, ON, Canada, 2020; pp. 36-39.

13. Chastas, P.; Theodosiou, T.; Bikas, D. Embodied energy in residential buildings-towards the nearly zero energy building: A literature review. Build. Environ. 2016, 105, 267-282. [CrossRef]

14. BS EN 15978, Sustainability of Construction Works, Assessment of Environmental Performance of Buildings: Calculation Method. Available online: https://standards.iteh.ai/catalog/standards/cen/62c22cef-5666-4719-91f9-c21cb6aa0ab3/en-1597 8-2011 (accessed on 7 September 2021).

15. International Energy Agency. Guideline for Design Professionals and Consultants Part 1: Basics for the Assessment of Embodied Energy and Embodied GHG Emissions Energy in Buildings and Communities Programme; International Energy Agency: Paris, France, 2016.

16. Ramesh, T.; Prakash, R.; Shukla, K.K. Life cycle energy analysis of buildings: An overview. Energy Build. 2010, 42, 1592-1600. [CrossRef]

17. Shrivastava, S.; Chini, A. Estimating energy consumption during construction of buildings: A contractor's perspective. In Proceedings of the World Sustainable Building Conference, Helsinki, Finland, 18-21 October 2011; pp. 18-21. 
18. Dixit, M.K.; Fernández-Solís, J.L.; Lavy, S.; Culp, C.H. Identification of parameters for embodied energy measurement: A literature review. Energy Build. 2010, 42, 1238-1247. [CrossRef]

19. OECD. Global Material Resources Outlook to 2060: Economic Drivers and Environmental Consequences; OECD: Paris, France, 2018.

20. Rajagopalan, N.; Bilec, M.M.; Landis, A.E. Life cycle assessment evaluation of green product labeling systems for residential construction. Int. J. Life Cycle Assess. 2012, 17, 753-763. [CrossRef]

21. Marini, A.; Passoni, C.; Belleri, A.; Feroldi, F.; Preti, M.; Metelli, G.; Riva, P.; Giuriani, E.; Plizzari, G. Combining seismic retrofit with energy refurbishment for the sustainable renovation of RC buildings: A proof of concept. Eur. J. Environ. Civ. Eng. 2017, 1-21. [CrossRef]

22. Feroldi, F.; Marini, A.; Badiani, B.; Plizzari, G.A.; Giuriani, E.; Riva, P.; Belleri, A. Energy efficiency upgrading, architectural restyling and structural retrofit of modern buildings by means of "engineered" double skin façade. In Proceedings of the 2nd International Conference on Structures \& Architecture (ICSA2013), Guimaraes, Portugal, 24-26 July 2013; pp. $1859-1866$.

23. Mora, T.D.; Righi, A.; Peron, F.; Romagnoni, P. Functional, Energy and Seismic Retrofitting in Existing Building: An Innovative System Based on xlam Technology. Energy Procedia 2015, 82, 486-492. [CrossRef]

24. Georgescu, E.-S.; Georgescu, M.; Macri, Z.; Marino, E.; Margani, G.; Meita, V.; Pana, R.; Cascone, S.; Petran, H.; Rossi, P.; et al. Seismic and Energy Renovation: A Review of the Code Requirements and Solutions in Italy and Romania. Sustainability 2018, 10, 1561. [CrossRef]

25. Basiricò, T.; Enea, D. Seismic and energy retrofit of the historic urban fabric of Enna (Italy). Sustainability 2018, 10, 1138. [CrossRef]

26. De Vita, M.; Mannella, A.; Sabino, A.; Marchetti, A. Seismic Retrofit Measures for Masonry Walls of Historical Buildings, from an Energy Saving Perspective. Sustainability 2018, 10, 984. [CrossRef]

27. Mora, T.D.; Pinamonti, M.; Teso, L.; Boscato, G.; Peron, F.; Romagnoni, P. Renovation of a school building: Energy retrofit and seismic upgrade in a school building in Motta Di Livenza. Sustainability 2018, 10, 969. [CrossRef]

28. Lamperti Tornaghi, M.; Loli, A.; Negro, P. Balanced Evaluation of Structural and Environmental Performances in Building Design. Buildings 2018, 8, 52. [CrossRef]

29. Loli, A.; Lamperti Tornaghi, M.; Negro, P. A method to include life-cycle analysis in earthquake design. In Proceedings of the 16th World Conference on Earthquake Engineering, Santiago, Chile, 9-13 January 2017.

30. Rossi, B.; Marique, A.-F.; Reiter, S. Life-cycle assessment of residential buildings in three different European locations, case study. Build. Environ. 2012, 51, 402-407. [CrossRef]

31. Wei, H.-H.; Skibniewski, M.J.; Shohet, I.M.; Yao, X. Lifecycle Environmental Performance of Natural-Hazard Mitigation for Buildings. J. Perform. Constr. Facil. 2016, 30, 04015042. [CrossRef]

32. Menna, C.; Asprone, D.; Jalayer, F.; Prota, A.; Manfredi, G. Assessment of ecological sustainability of a building subjected to potential seismic events during its lifetime. Int. J. Life Cycle Assess. 2013, 18, 504-515. [CrossRef]

33. Hasik, V.; Chhabra, J.P.S.; Warn, G.P.; Bilec, M.M. Review of approaches for integrating loss estimation and life cycle assessment to assess impacts of seismic building damage and repair. Eng. Struct. 2018, 175, 123-137. [CrossRef]

34. Applied Technology Council for the Federal Emergency Management Agency. Techniques for the Seismic Rehabilitation of Existing Buildings; Applied Technology Council for the Federal Emergency Management Agency: Washington, DC, USA, 2006; Volume FEMA 547.

35. Applied Technology Council for the Federal Emergency Management Agency. Next-Generation Methodology for Seismic Performance Assessment of Buildings; Applied Technology Council for the Federal Emergency Management Agency: Washington, DC, USA, 2012; Volume FEMA P-58.

36. Welsh-Huggins, S.J.; Liel, A.B. A life-cycle framework for integrating green building and hazard-resistant design: Examining the seismic impacts of buildings with green roofs. Struct. Infrastruct. Eng. 2017, 13, 19-33. [CrossRef]

37. Chiu, C.K.; Chen, M.R.; Chiu, C.H. Financial and Environmental Payback Periods of Seismic Retrofit Investments for Reinforced Concrete Buildings Estimated Using a Novel Method. J. Archit. Eng. 2013, 19, 112-118. [CrossRef]

38. Feese, C.; Li, Y.; Bulleit, W.M. Assessment of Seismic Damage of Buildings and Related Environmental Impacts. J. Perform. Constr. Facil. 2015, 29, 04014106. [CrossRef]

39. Padgett, J.E.; Li, Y. Risk-Based Assessment of Sustainability and Hazard Resistance of Structural Design. J. Perform. Constr. Facil. 2016, 30, 04014208. [CrossRef]

40. Alirezaei, M.; Noori, M.; Tatari, O.; Mackie, K.R.; Elgamal, A. BIM-based Damage Estimation of Buildings under Earthquake Loading Condition. Procedia Eng. 2016, 145, 1051-1058. [CrossRef]

41. Comber, M.V.; Poland, C.D. Disaster Resilience and Sustainable Design: Quantifying the Benefits of a Holistic Design Approach. In Proceedings of the Structures Congress, Pittsburgh, PA, USA, 2-4 May 2013; American Society of Civil Engineers: Reston, VA, USA, 2013; pp. 2717-2728.

42. Simonen, K.; Merrifield, S.; Almufti, I.; Strobel, K.; Tipler, J. Integrating Environmental Impacts as Another Measure of Earthquake Performance for Tall Buildings in High Seismic Zones. In Proceedings of the Structures Congress, Portland, OR, USA, 23-25 April 2015; American Society of Civil Engineers: Reston, VA, USA, 2015; pp. 933-944.

43. Welsh-Huggins, S.J.; Liel, A.B. Evaluating Multiobjective Outcomes for Hazard Resilience and Sustainability from Enhanced Building Seismic Design Decisions. J. Struct. Eng. 2018, 144, 04018108. [CrossRef]

44. Simonen, K.; Huang, M.; Aicher, C.; Morris, P. Embodied carbon as a proxy for the environmental impact of earthquake damage repair. Energy Build. 2018, 164, 131-139. [CrossRef] 
45. Sarkisian, M.P. Design of environmentally responsible structures in regions of high seismic risk. Struct. Infrastruct. Eng. 2014, 10, 849-864. [CrossRef]

46. Welsh-Huggins, S.J.; Liel, A.B. Integrating hazard-induced damage and environmental impacts in building life-cycle assessments. In Proceedings of the 2014 International Symposium of Life-Cycle Civil Engineering, Tokyo, Japan, 16-19 November 2014.

47. Belleri, A.; Marini, A. Does seismic risk affect the environmental impact of existing buildings? Energy Build. 2016, 110, 149-158. [CrossRef]

48. Hossain, K.A.; Gencturk, B. Life-Cycle Environmental Impact Assessment of Reinforced Concrete Buildings Subjected to Natural Hazards. J. Archit. Eng. 2016, 22, A4014001. [CrossRef]

49. Gencturk, B.; Hossain, K.; Lahourpour, S. Life cycle sustainability assessment of RC buildings in seismic regions. Eng. Struct. 2016, 110, 347-362. [CrossRef]

50. Chhabra, J.P.S.; Hasik, V.; Bilec, M.M.; Warn, G.P. Probabilistic Assessment of the Life-Cycle Environmental Performance and Functional Life of Buildings due to Seismic Events. J. Archit. Eng. 2018, 24, 04017035. [CrossRef]

51. Menna, C.; Caruso, M.C.; Asprone, D.; Prota, A. Environmental sustainability assessment of structural retrofit of masonry buildings based on LCA. Eur. J. Environ. Civ. Eng. 2016, 1-10. [CrossRef]

52. Terracciano, G.; Di Lorenzo, G.; Formisano, A.; Landolfo, R. Cold-formed thin-walled steel structures as vertical addition and energetic retrofitting systems of existing masonry buildings. Eur. J. Environ. Civ. Eng. 2015, 19, 850-866. [CrossRef]

53. Napolano, L.; Menna, C.; Asprone, D.; Prota, A.; Manfredi, G. LCA-based study on structural retrofit options for masonry buildings. Int. J. Life Cycle Assess. 2015, 20, 23-35. [CrossRef]

54. Ferreira, J.; Duarte Pinheiro, M.; de Brito, J. Economic and environmental savings of structural buildings refurbishment with demolition and reconstruction-A Portuguese benchmarking. J. Build. Eng. 2015, 3, 114-126. [CrossRef]

55. Vitiello, U.; Salzano, A.; Asprone, D.; Di Ludovico, M.; Prota, A. Life-cycle assessment of seismic retrofit strategies applied to existing building structures. Sustainability 2016, 8, 1275. [CrossRef]

56. Formisano, A.; Chiumiento, G.; Di Lorenzo, G.; Landolfo, R. Innovative and traditional seismic retrofitting techniques of an exisiting RC school building: Life cycle assessment and performance ranking through the TOPSIS method. Constr. Met. 2017, 84-93. Available online: https://www.researchgate.net/publication/316845993_Innovative_and_traditional_seismic_ retrofitting_techniques_of_an_existing_RC_school_building_life_cycle_assessment_and_performance_ranking_through_the_ TO_PSIS_method (accessed on 7 September 2021).

57. Uzun, E.T.; Secer, M. Evaluation of Building Retrofitting Alternatives from Sustainability Perspective. Procedia Eng. 2017, 171, 1137-1146. [CrossRef]

58. Ribakov, Y.; Halperin, I.; Pushkar, S. Seismic Resistance and Sustainable Performance of Retrofitted Buildings by Adding Stiff Diaphragms or Seismic Isolation. J. Archit. Eng. 2018, 24, 04017028. [CrossRef]

59. Dattilo, C.; Negro, P.; Landolfo, R. An Integrated Approach for Sustainability (IAS): Life Cycle Assessment (LCA) as a Supporting Tool for Life Cycle Costing (LCC) and Social Issues. In Proceedings of the International Conference on on Sustainable Building and Affordable To All, Algarve, Portugal, 17-19 March 2010; pp. 721-728.

60. Lützkendorf, T.; Balouktsi, M.; Frischknecht, R. Evaluation of Embodied Energy and $\mathrm{CO}_{2 e q}$ for Building Construction (Annex 57), Subtask 1: Basics, Actors and Concepts; International Energy Agency: Paris, France, 2016.

61. Keskin, F.S.; Martinez-Vazquez, P.; Baniotopoulos, C. Sustainable structural intervention methodology for vulnerable buildings from a lifecycle perspective. In Proceedings of the IOP Conference Series: Earth and Environmental Science, Thessaloniki, Greece, 23-25 October 2019; p. 012051.

62. ISO. Environmental Management_Life Cycle Assessment-Principles and Framework. 2006, pp. 1-20. Available online: https: / / www.iso.org/standard/37456.html (accessed on 7 September 2021).

63. FEMA. Seismic Performance Assessment of Buildings, Methodology for Assessing Environmental Impacts; FEMA: Washington, DC, USA, 2012; Volume FEMA P-58-4, pp. 1-271.

64. Romano, E.; Negro, P.; Taucer, F. Seismic Performance Assessment Addressing Sustainability and Energy Efficiency; Publications Office of the European Union: Paris, France, 2014; Volume EUR 26432.

65. Beyhan, G.; Keskinsezer, A.; Kafadar, Ö. Analysis of strong ground motion data from the Van earthquake (Turkey), 2011. Geomech. Geophys. Geo-Energy Geo-Resour. 2019, 5, 253-270. [CrossRef]

66. Marteinsson, B. Service Life Estimation in the Design of Buildings: A Development of the Factor Method. Ph.D. Thesis, University of Gävle, Gavle, Sweden, 2005.

67. Soronis, G. Standards for design life of buildings: Utilization in the design process. Constr. Build. Mater. 1996, 10, 487-490. [CrossRef]

68. Hernández-Moreno, S. The Method By Factors To Estimate Service Life in Uildings Projects According To Norm Iso 15686. Manag. Res. Pract. 2012, 4, 5-11.

69. ASMI. Life Cycle Assessment of UBC Biological Sciences Complex Renew Project; ASMI: Ottawa, ON, Canada, 2011.

70. Athena Sustainable Materials Institute. ASMI Technical Details. Available online: http://www.athenasmi.org/resources/aboutlca/technical-details/ (accessed on 4 October 2020).

71. Athena Sustainable Materials Institute. Athena Impact Estimator for Buildings V 4.5 Users Manual, Software and Database Overview; Athena Sustainable Materials Institute: Ottawa, ON, Canada, 2013. 
72. Athena Sustainable Materials Institute. Impact Estimator for Buildings. Available online: https://calculatelca.com/software/ impact-estimator/ (accessed on 2 October 2020).

73. Hauke, B.; Siebers, R. Life Cycle Assessment Comparison of a Typical Single Storey Building; bauforumstah: Düsseldorf, Germany, 2011.

74. Martinez Vazquez, P. Procedimiento de Construccion del Refuerzo Exterior de Hospital 20 de Noviembre (Construction Procedure of the External Reinforcement of Hospital November 20). Bachelor's Thesis, Universidad Nacional Autonoma de Mexico, Mexico City, Mexico, 1995.

75. Almanza, L.M. Proyecto Del Refuerzo Estructural Interior a Base De Contraventeos Metalicos Del Hospital 20 De Noviembre, En La Ciudad De Mexico (Project of the Interior Structural Reinforcement Based on Metallic Buttresses of the 20 de Noviembre Hospital, in Mexico City). Bachelor's Thesis, Universidad Nacional Autonoma de Mexico, Mexico City, Mexico, 1996.

76. Morán-Rodríguez, S.; Novelo-Casanova, D.A. A methodology to estimate seismic vulnerability of health facilities. Case study: Mexico City, Mexico. Nat. Hazards 2018, 90, 1349-1375. [CrossRef]

77. RCDF. Normas Tecnicas Complementarias del Reglamento de Construcciones Para el Distrito Federal (Complementary Technical Norms of the Construction Regulations for the Federal District); RCDF: Mexico City, Mexico, 1987; pp. 1-287.

78. Meléndez, R.G. Costos Paramétricos (Parametric Costs); Instituto Mexicano de Ingeniería de Costos: Mexico City, Mexico, 2014; ISBN 0319990804094.

79. PEEB. Building Sector Brief: Mexico; PEEB: Programme for Energy Efficiency in Buildings: Paris, France, 2018.

80. Ji, R.; Qu, S. Investigation and evaluation of energy consumption performance for hospital buildings in China. Sustainability 2019, 11, 1724. [CrossRef] 